Supporting Information

\title{
Palladium-Catalyzed Intramolecular Allylic Amidation via Decarboxylative Aromatization: Synthesis of $N$-Allyl- $N$-aryl Sulfonamides
}

Tzu-Lun Liu, Meng-Li Jhou, Cheng-En Hsieh, Chia-Jung Lin, Hsiu-Hui Su, and Chih-Ming Chou*

Department of Applied Chemistry, National University of Kaohsiung, 700, Kaohsiung University Road, Nanzih District, 81148 Kaohsiung, Taiwan

E-mail:cmchou@nuk.edu.tw 
Table of Contents

Scheme of 1-alkyl cyclohexa-2,5-dienyl ketoesters 1a-1i...........................................................S3

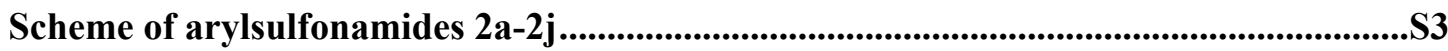

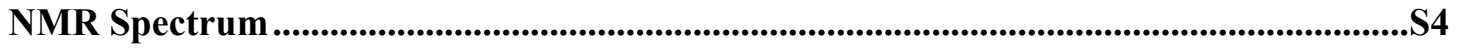


Scheme of 1-alkyl cyclohexa-2,5-dienyl ketoesters 1a-1i

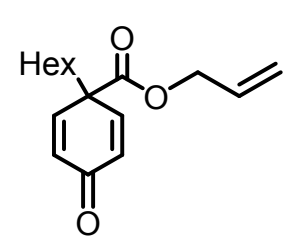

$1 a$

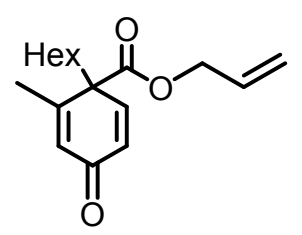

1b<smiles>C=CCOC(=O)C1(C)C=CC(=O)C=C1</smiles>

1c<smiles>C=CCOC(=O)C1(CC(=O)OC)C=CC(=O)C=C1C</smiles>

1d<smiles>[R]C1(C(=O)OC(C)C=C)C=CC(=O)C=C1</smiles>

$1 \mathrm{e}$<smiles>[R1]C1(C(=O)OCC=C(C)C)C=CC(=O)C=C1</smiles>

$1 f$<smiles>[14CH3]/C=C/COC(=O)C1([14CH3])C=CC(=O)C=C1</smiles>

19<smiles>[14CH3]C1(C(=O)OC/C=C/c2ccccc2)C=CC(=O)C=C1</smiles>

$1 \mathrm{~h}$<smiles>C=CC(OC(=O)C1([14CH3])C=CC(=O)C=C1)c1ccccc1</smiles>

$1 \mathbf{i}$

Scheme of arylsulfonamides $\mathbf{2 a - 2 j}$<smiles>NS(=O)(=O)c1ccccc1</smiles>

2a<smiles>COc1ccc(S(=O)(=O)ON)cc1</smiles>

$2 f$<smiles>Cc1ccccc1S(N)(=O)=O</smiles>

2b<smiles>NS(=O)(=O)c1cccc(Cl)c1</smiles>

$2 g$<smiles>Cc1ccc(S(=O)(=O)ON)cc1</smiles>

2c<smiles>NS(=O)(=O)c1ccc(Cl)cc1</smiles>

$2 \mathrm{~h}$<smiles>NOS(=O)(=O)c1ccc(F)cc1</smiles>

2d<smiles>NS(=O)(=O)c1ccc(Br)cc1</smiles>

$2 \mathbf{i}$<smiles>NOS(=O)(=O)c1ccc([N+](=O)[O-])cc1</smiles>

$2 e$

2j 
NMR Spectrum
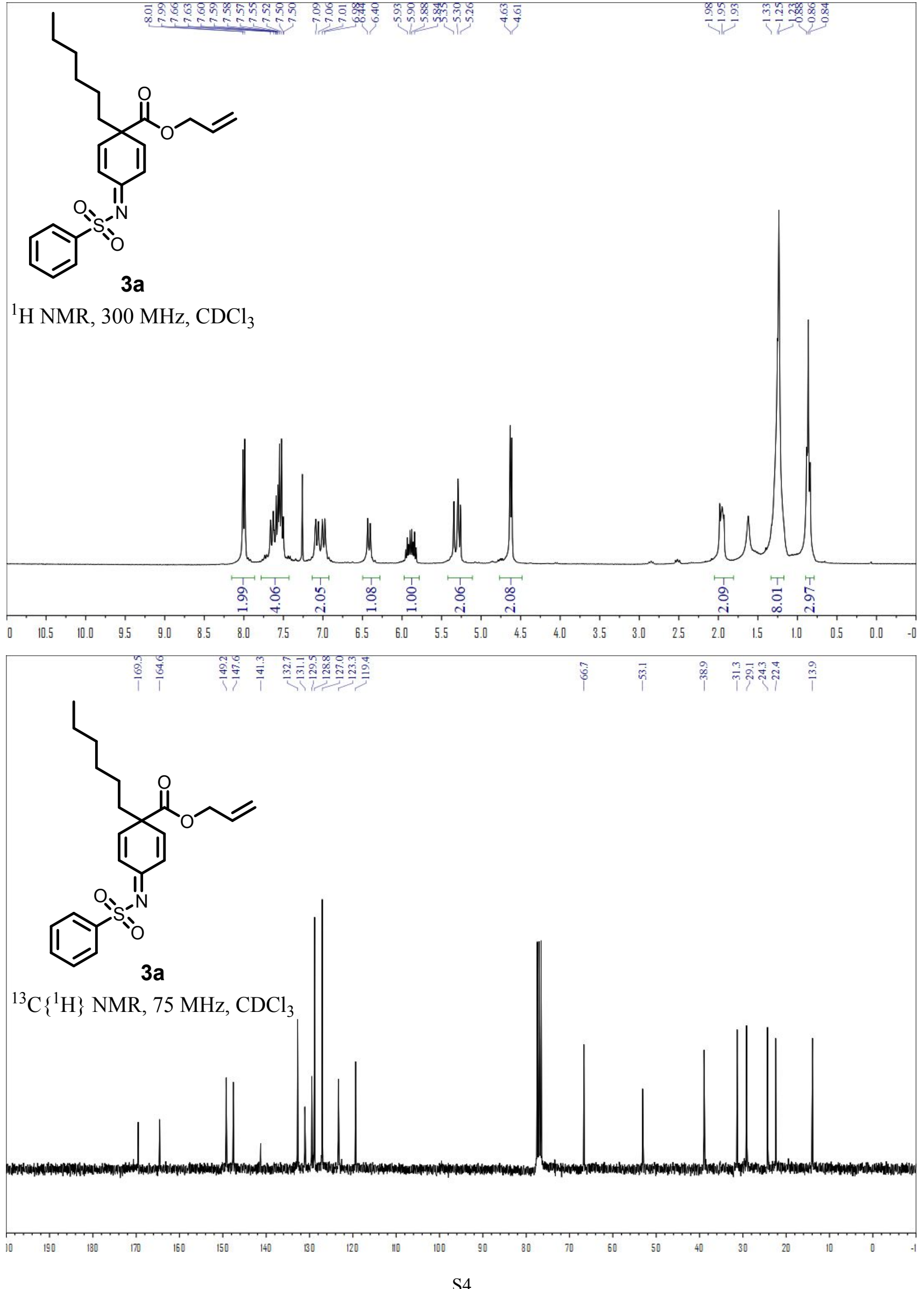

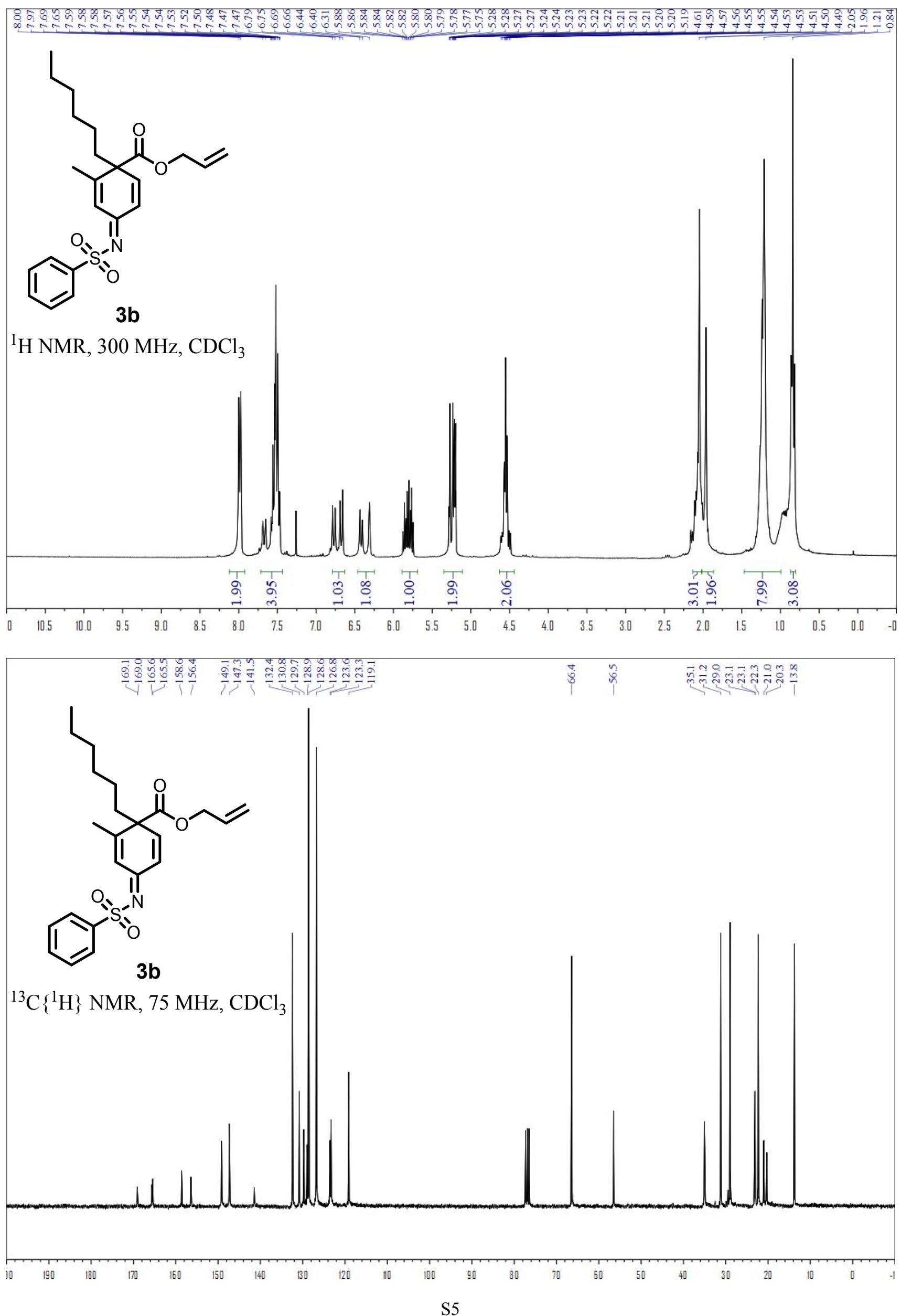

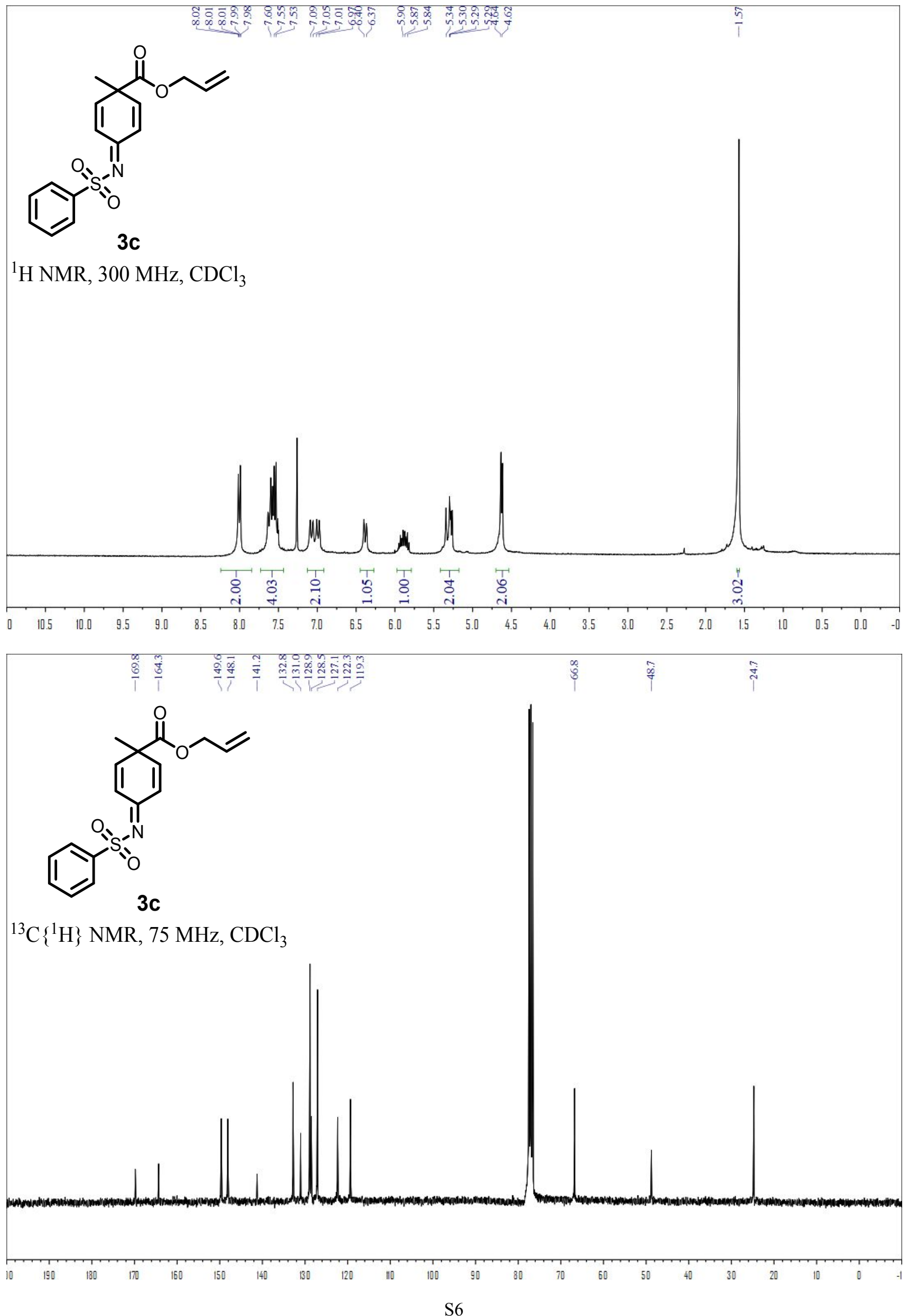

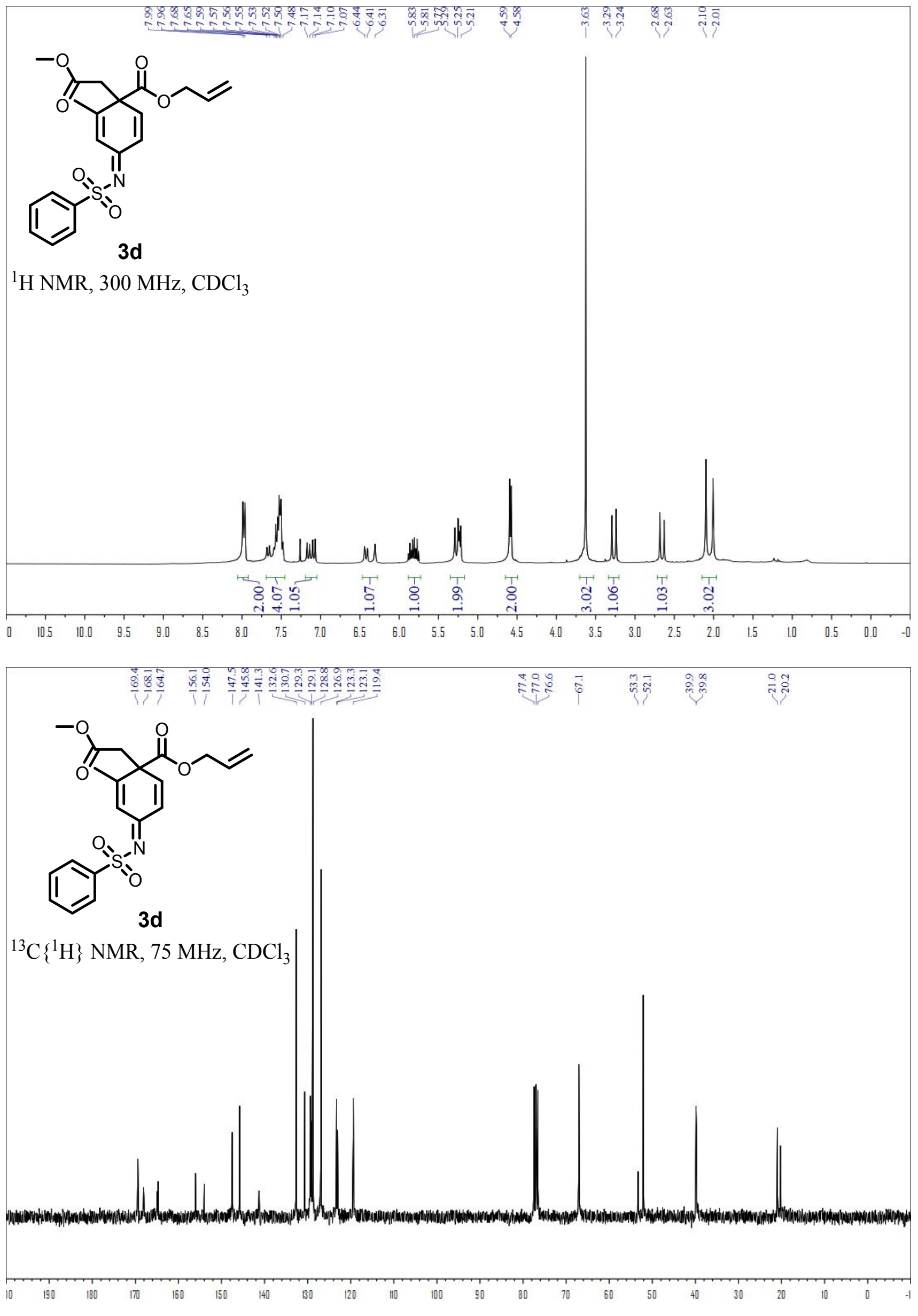

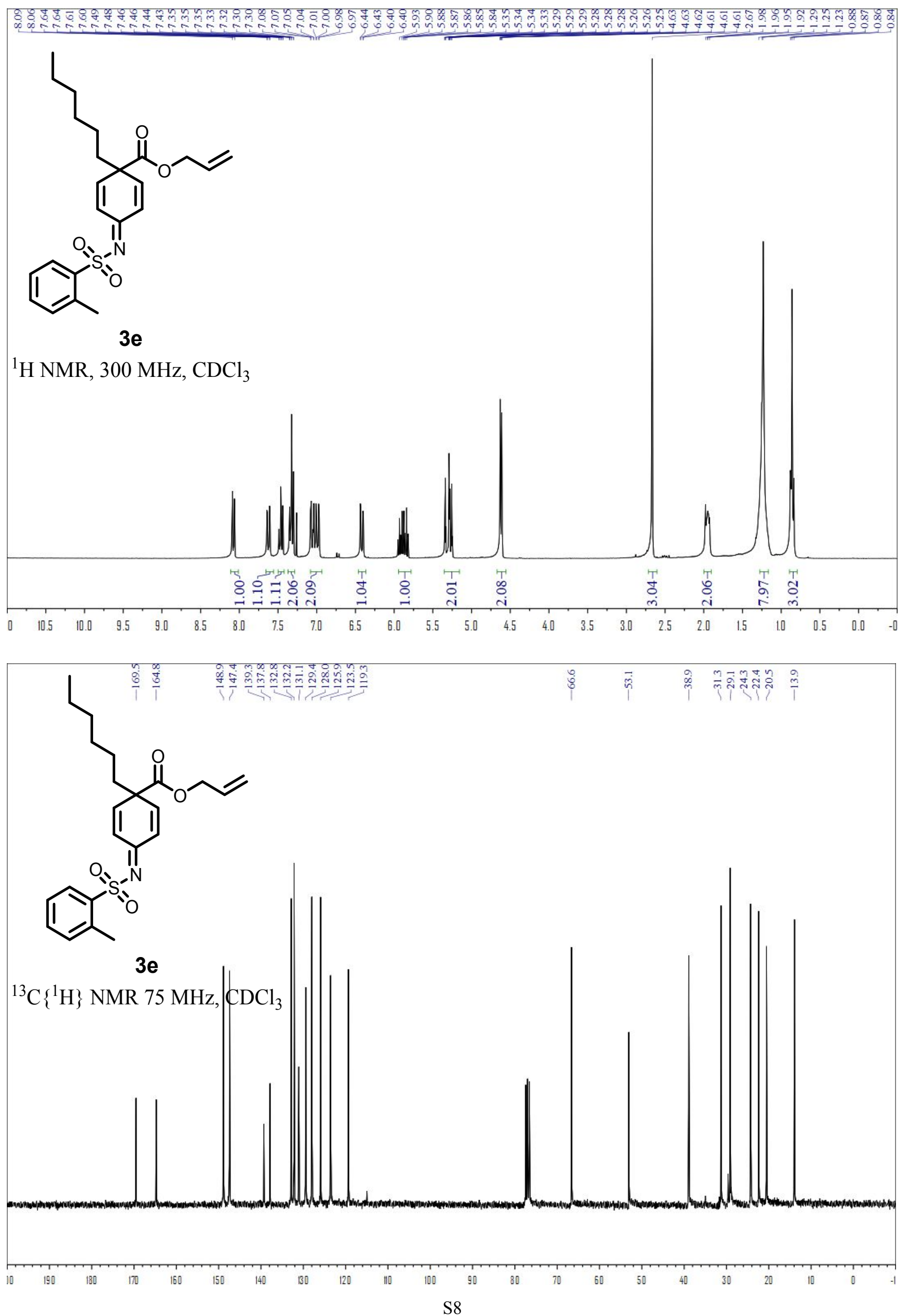

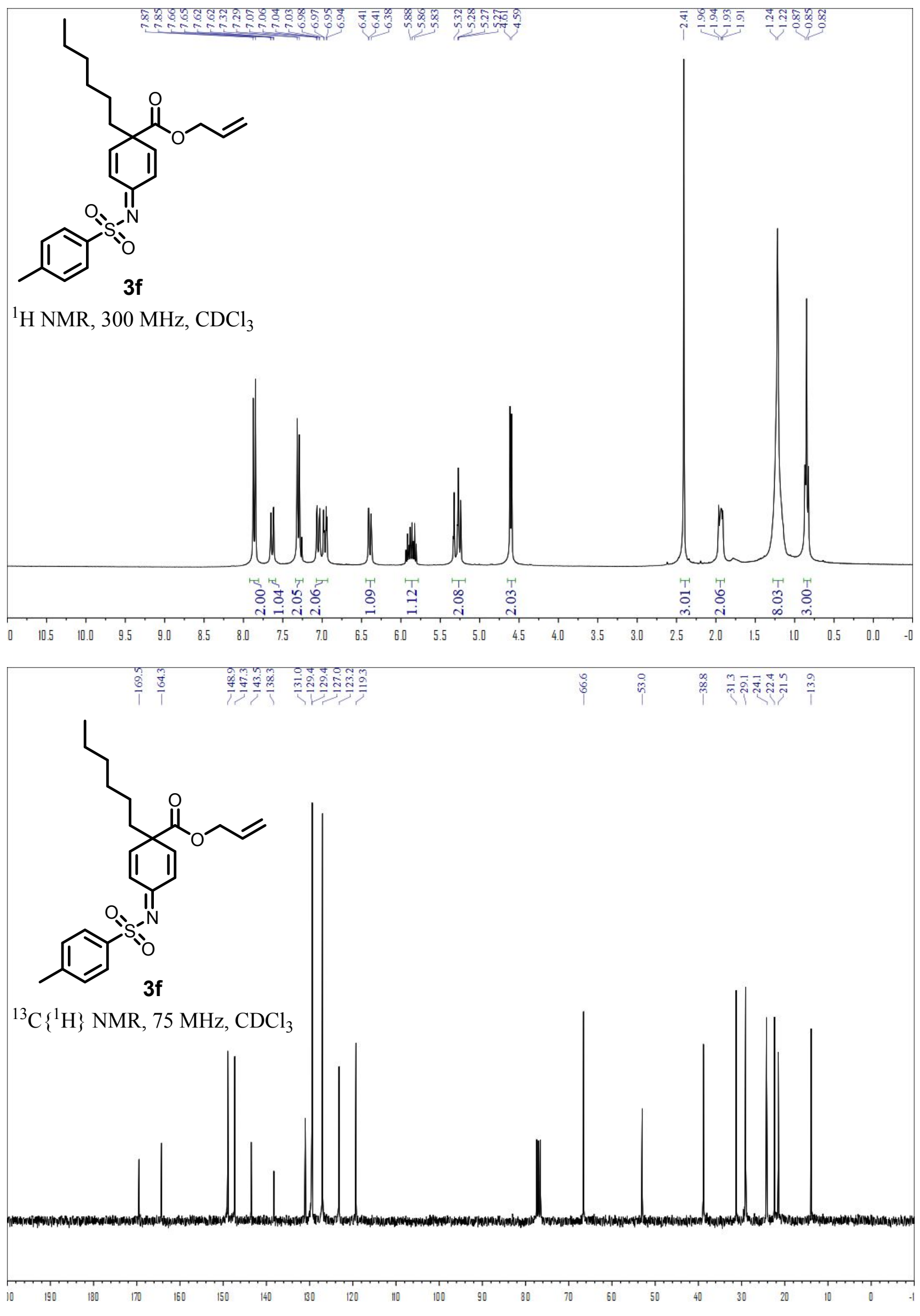

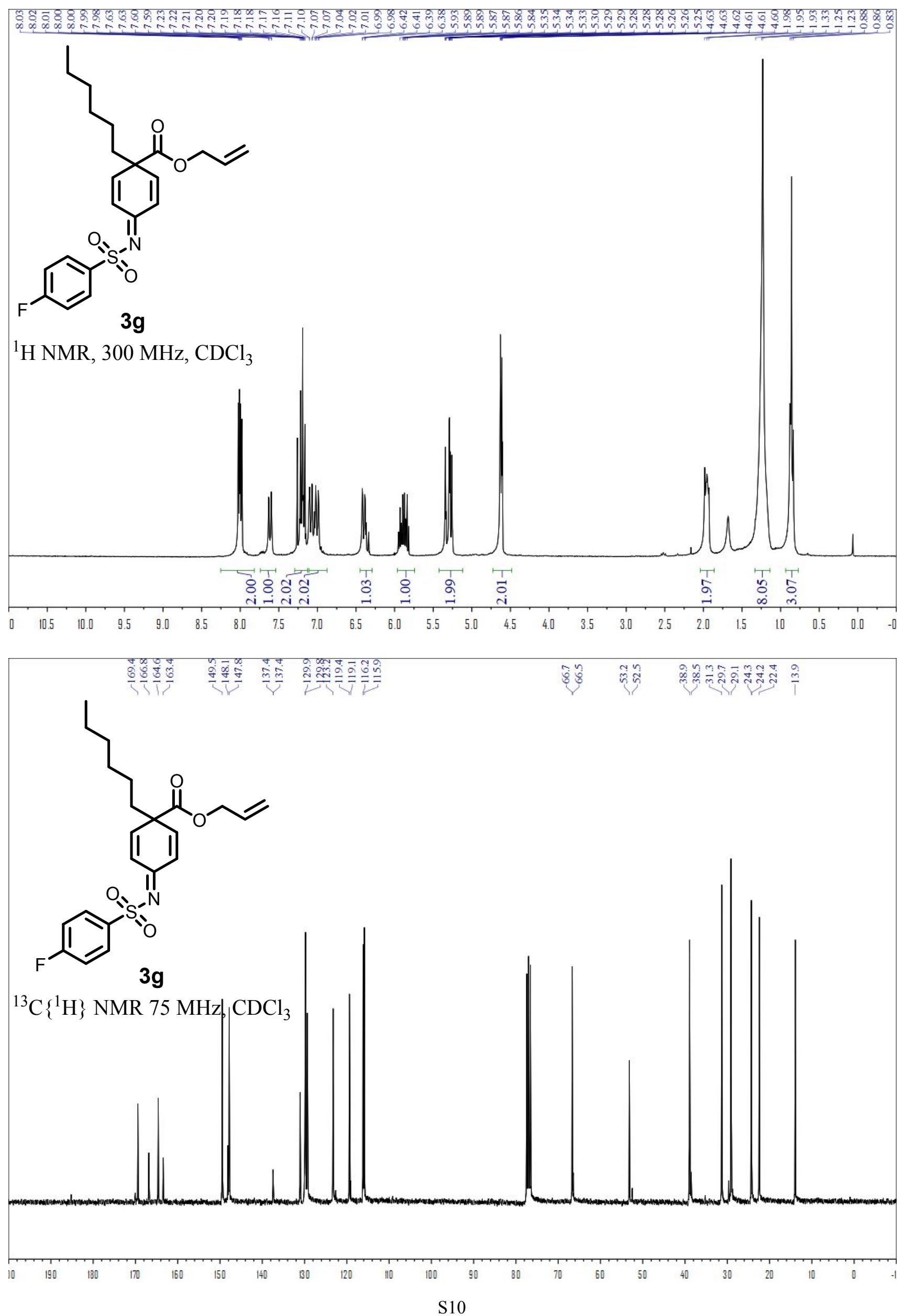


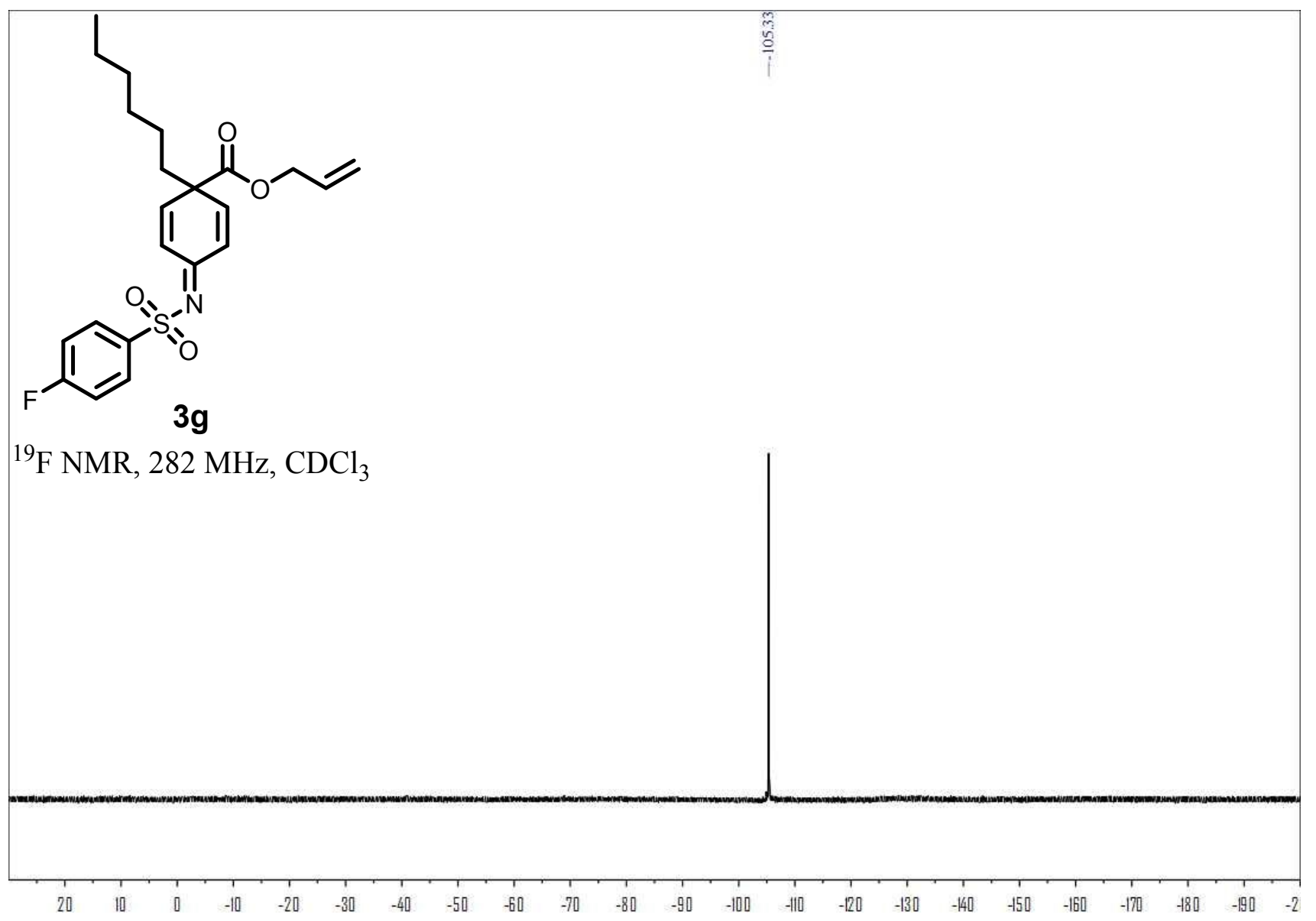



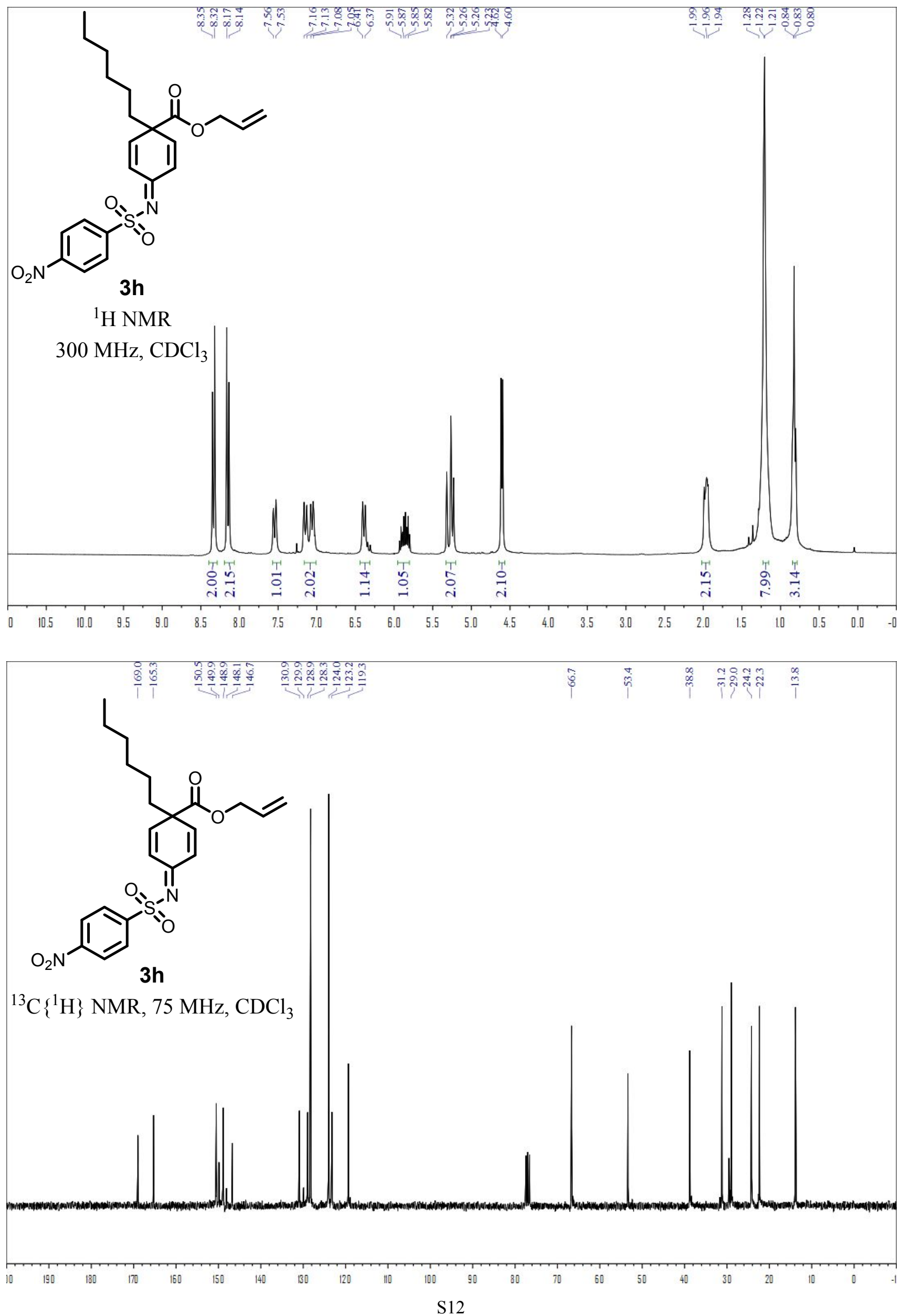

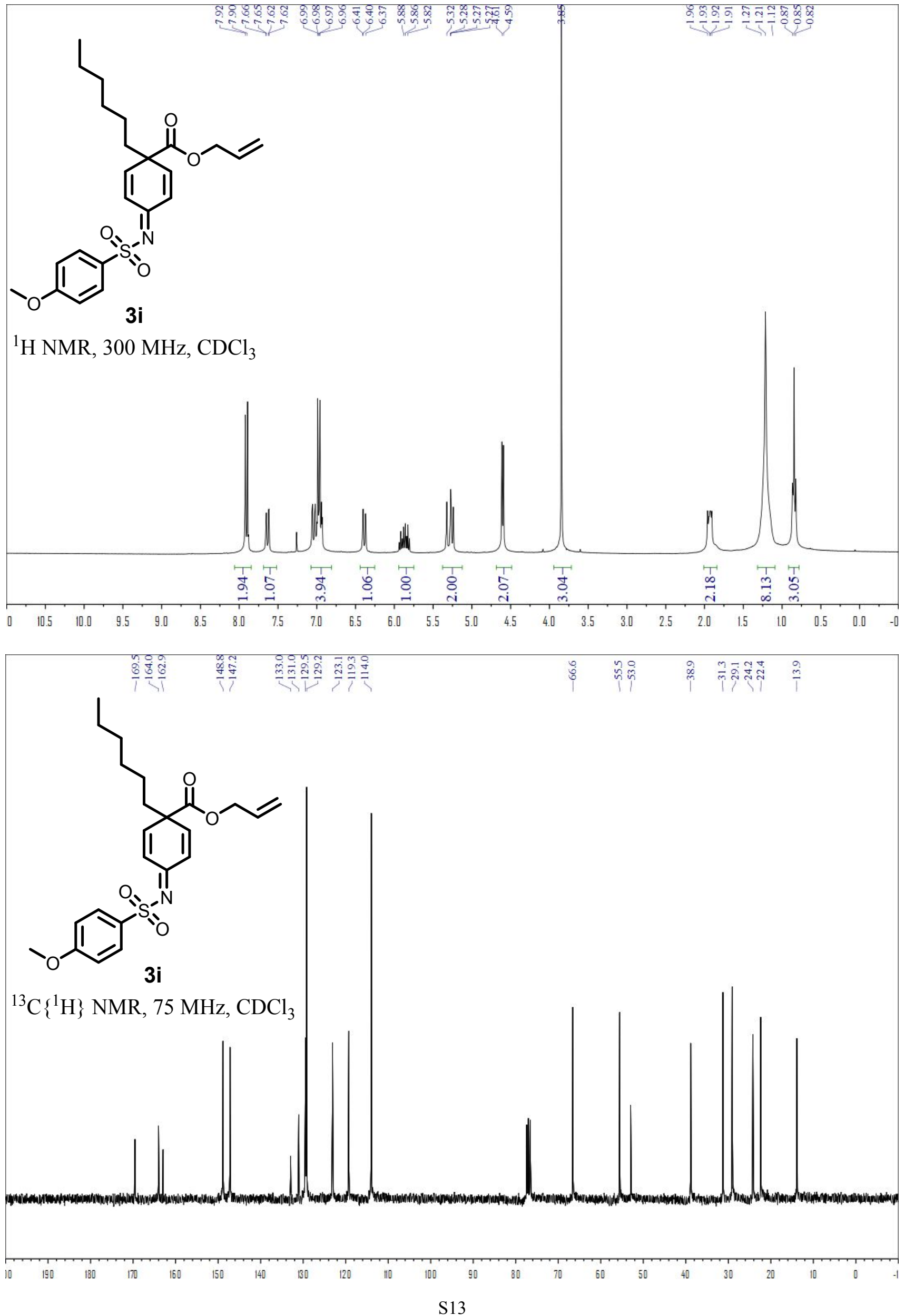

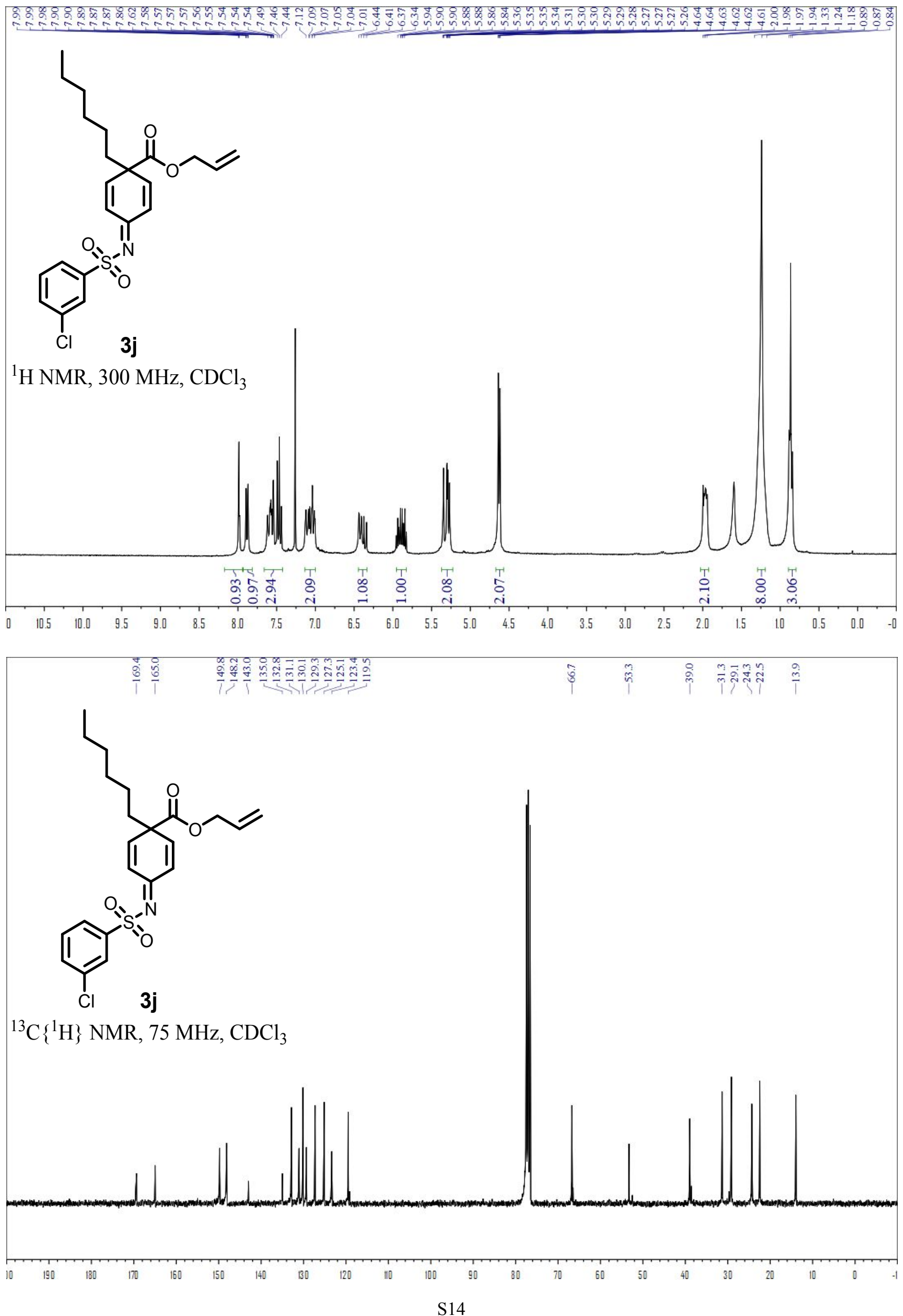


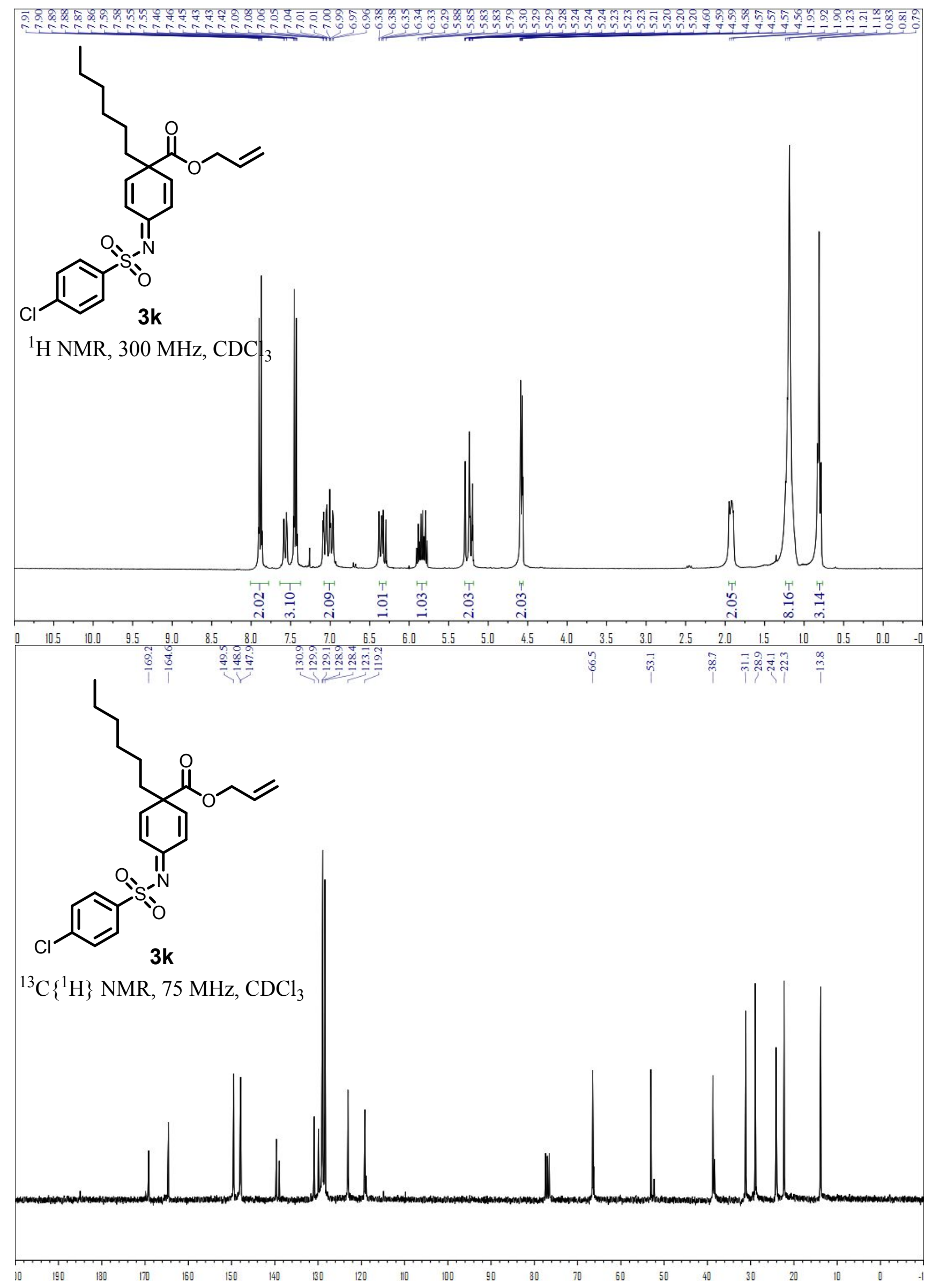




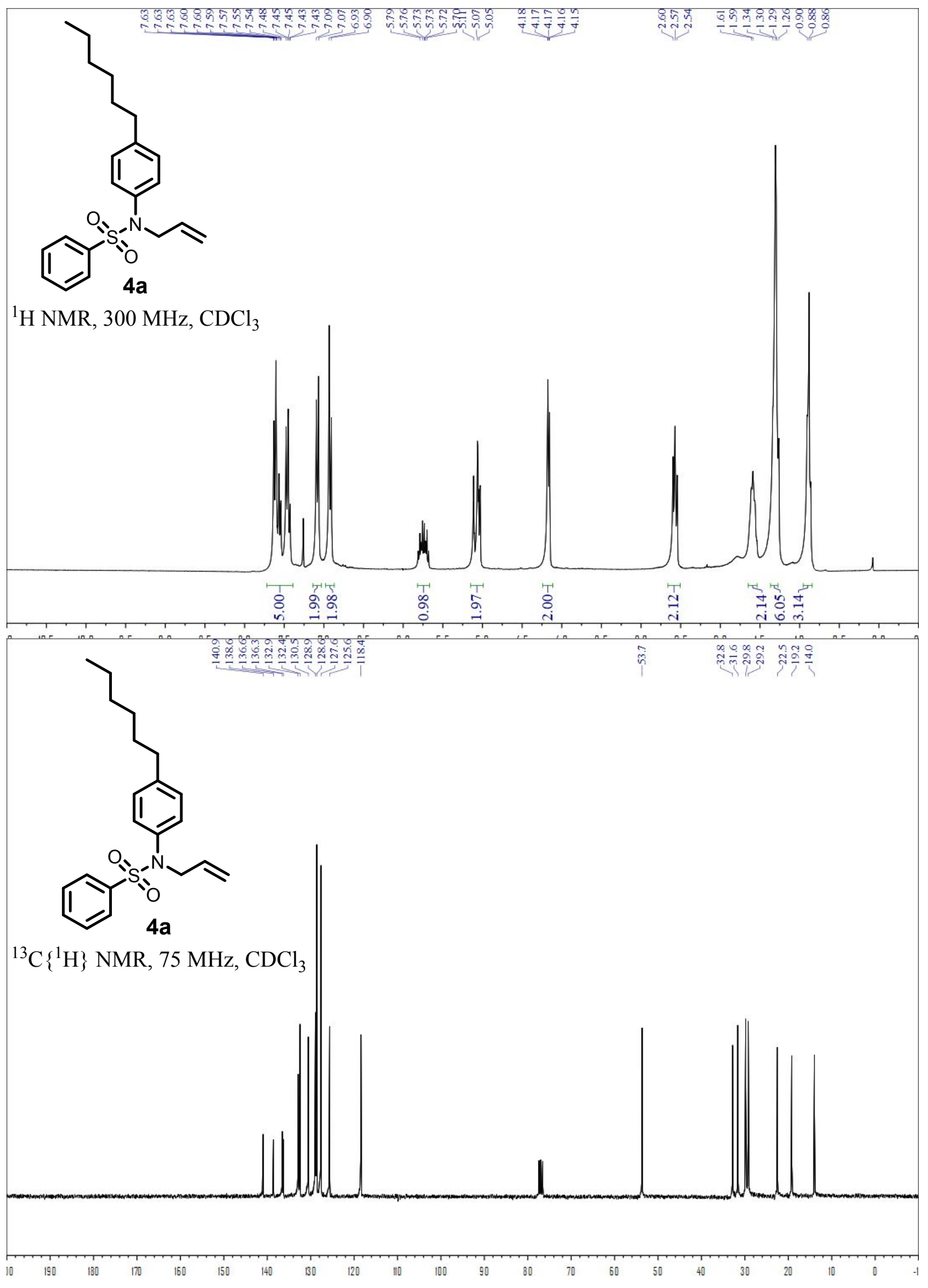




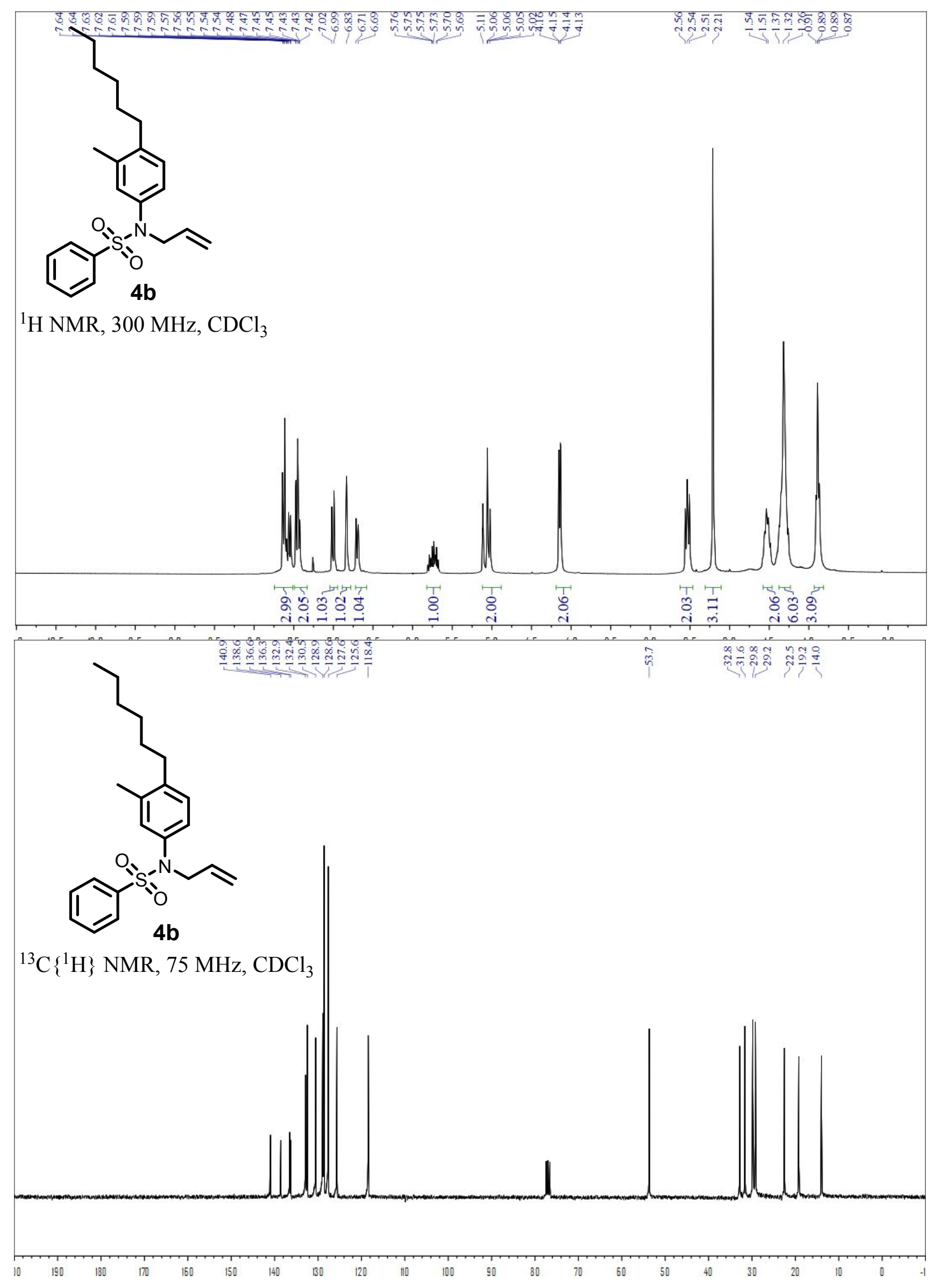



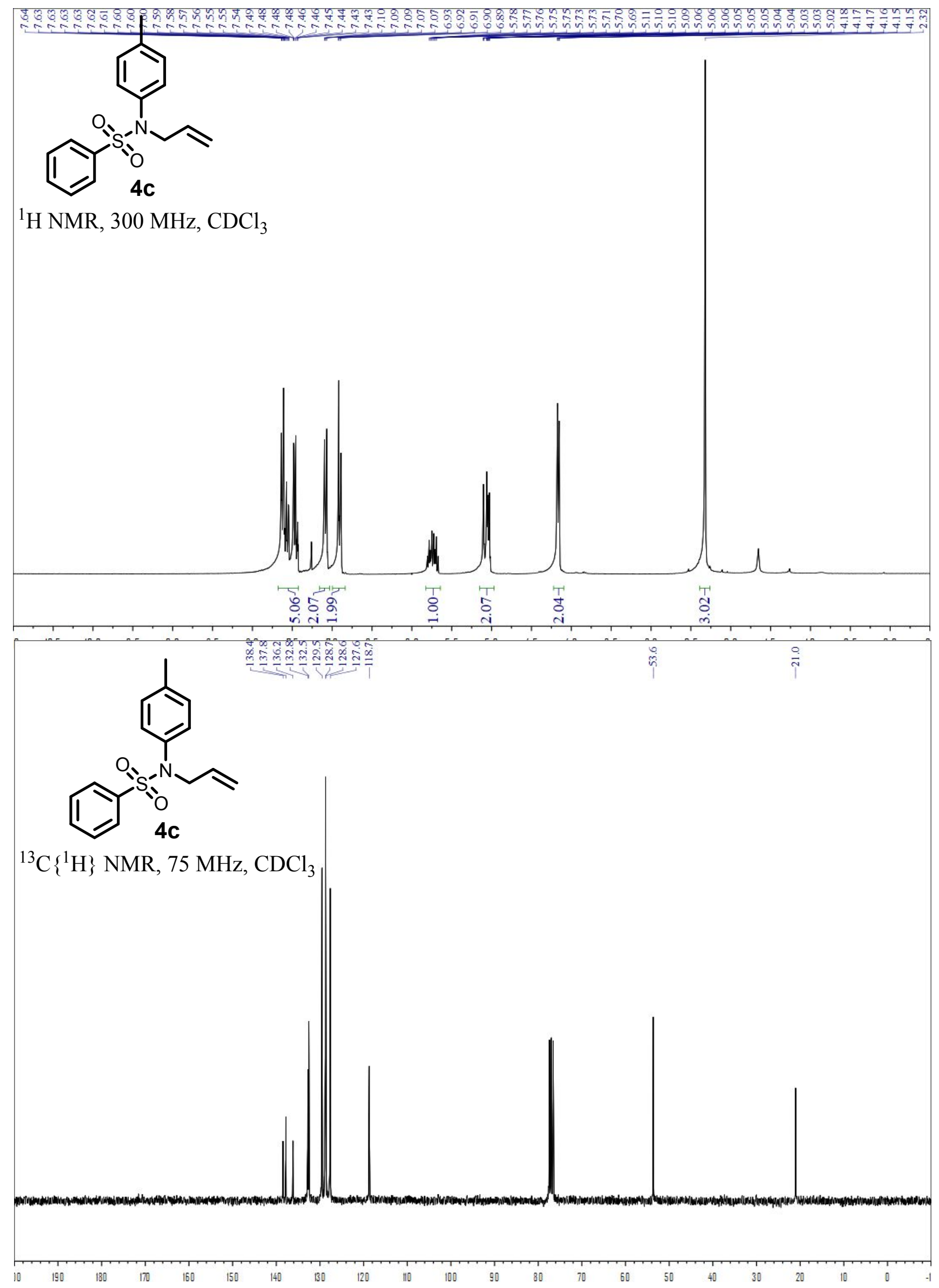


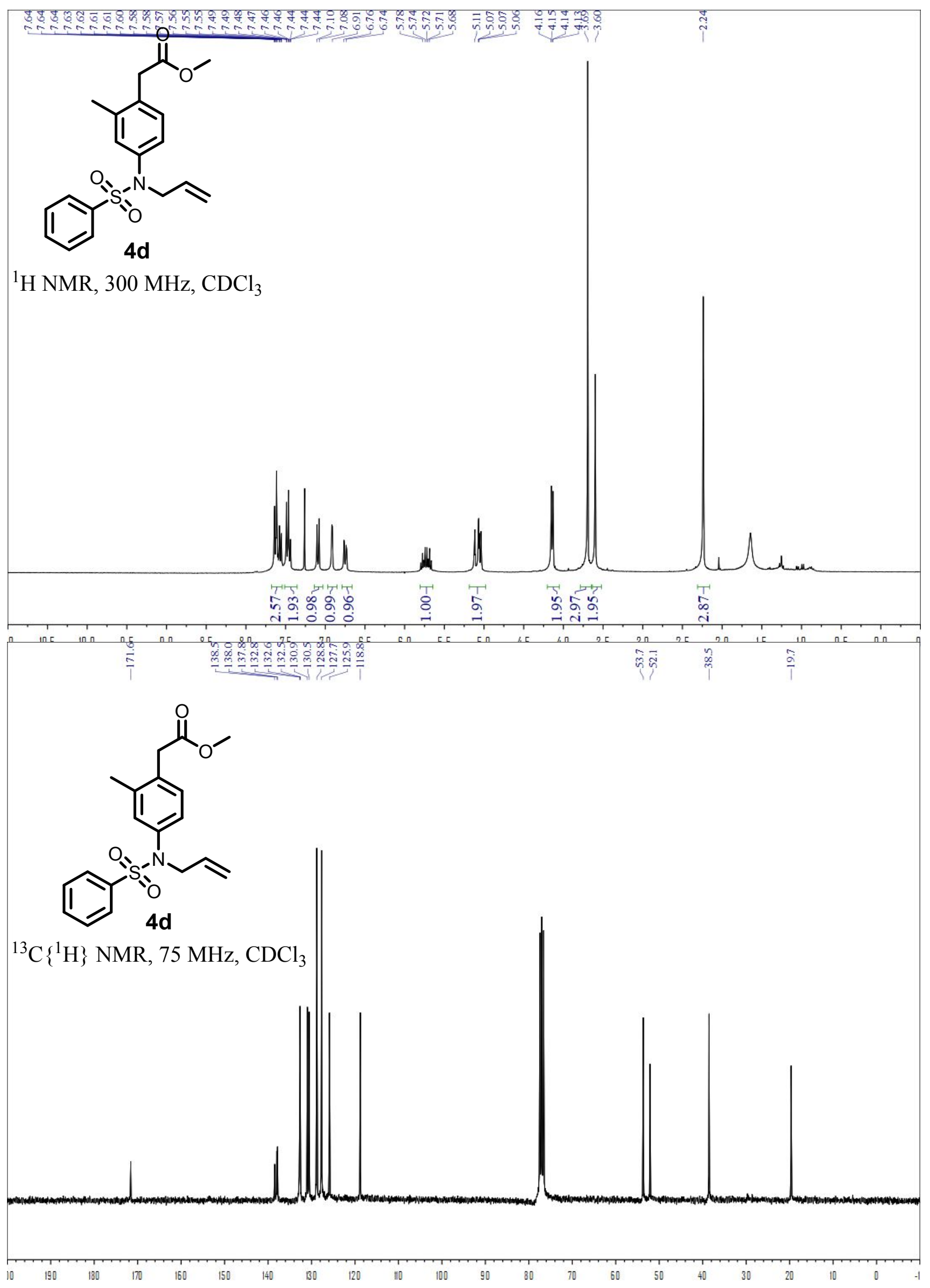



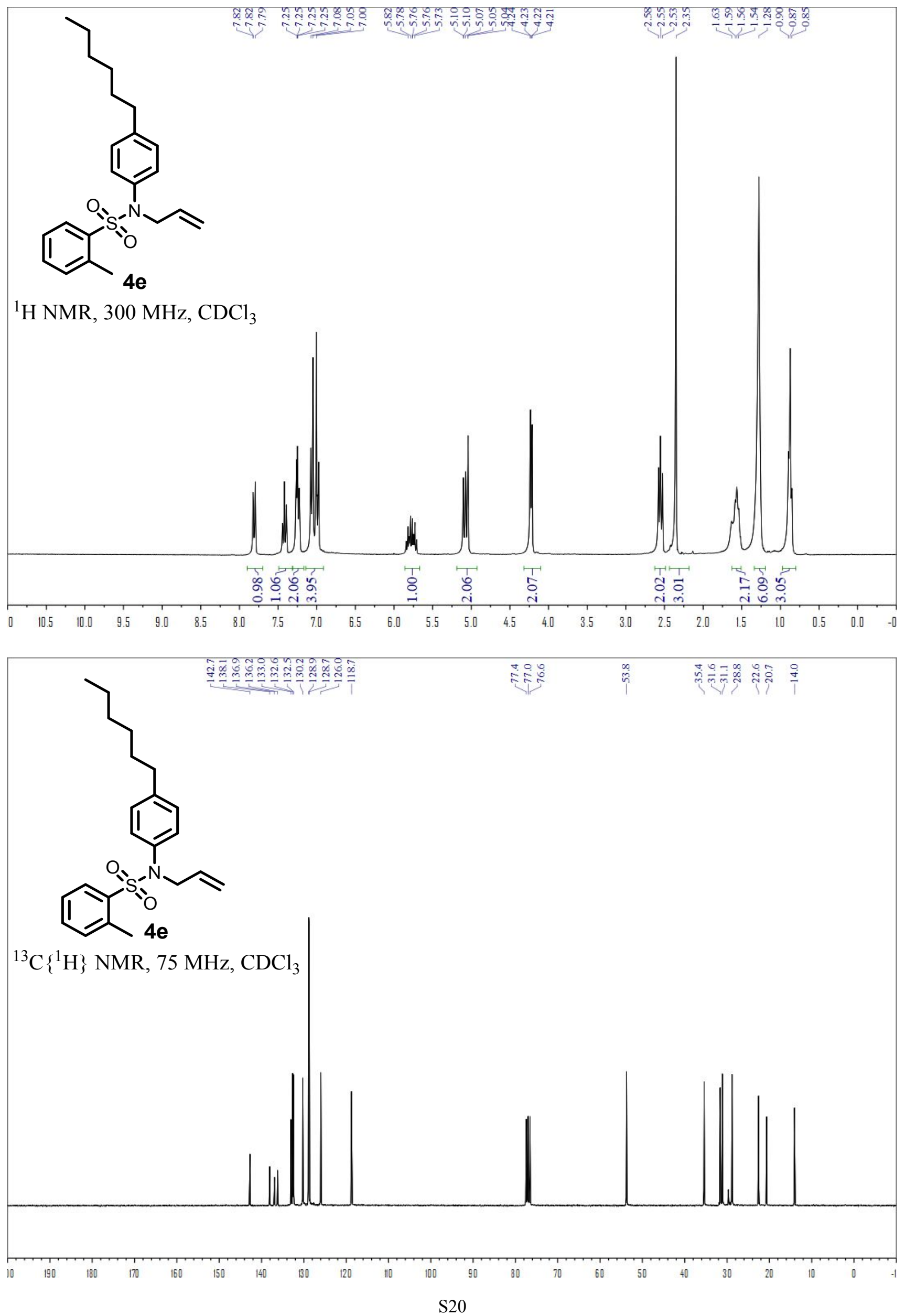

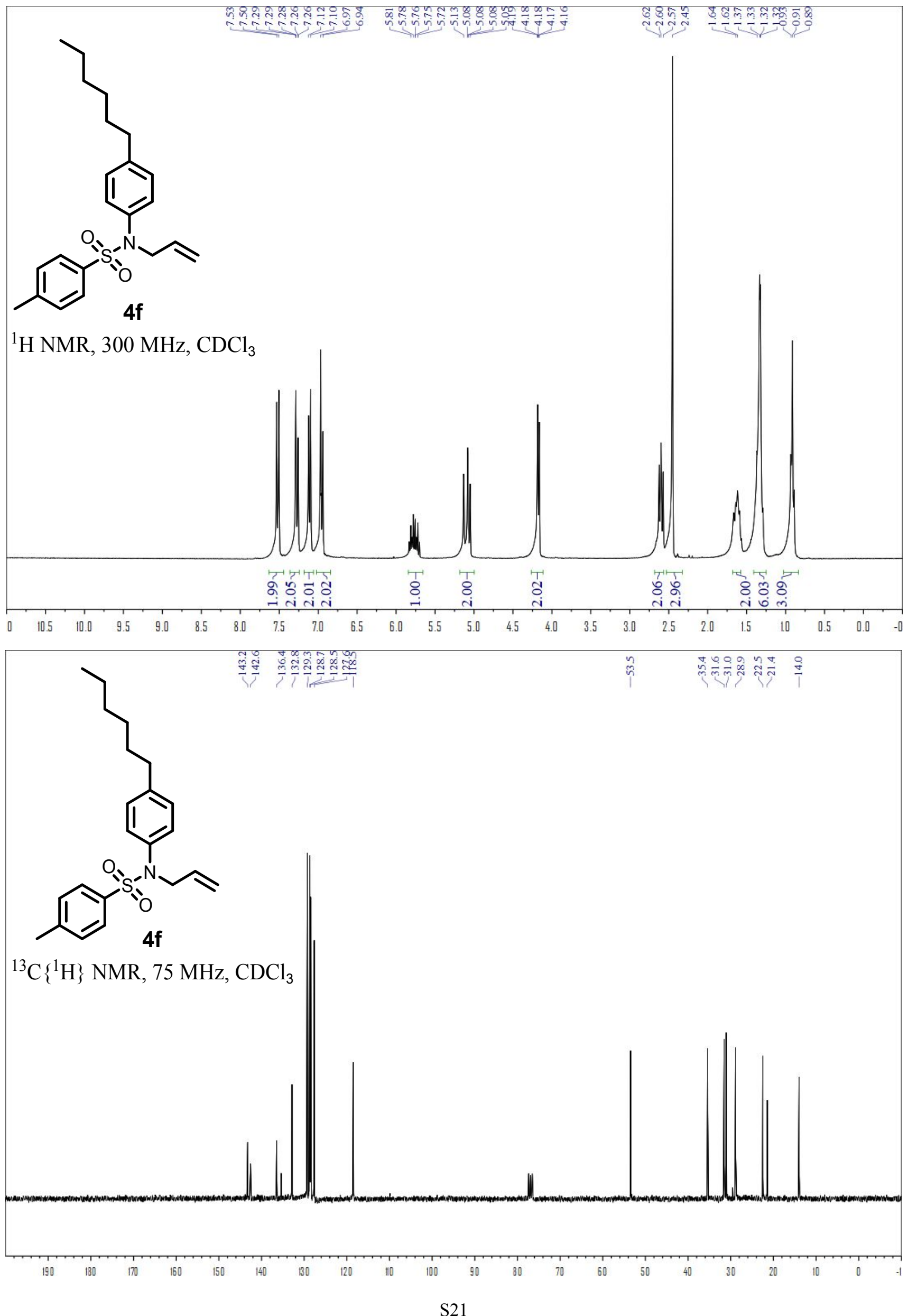

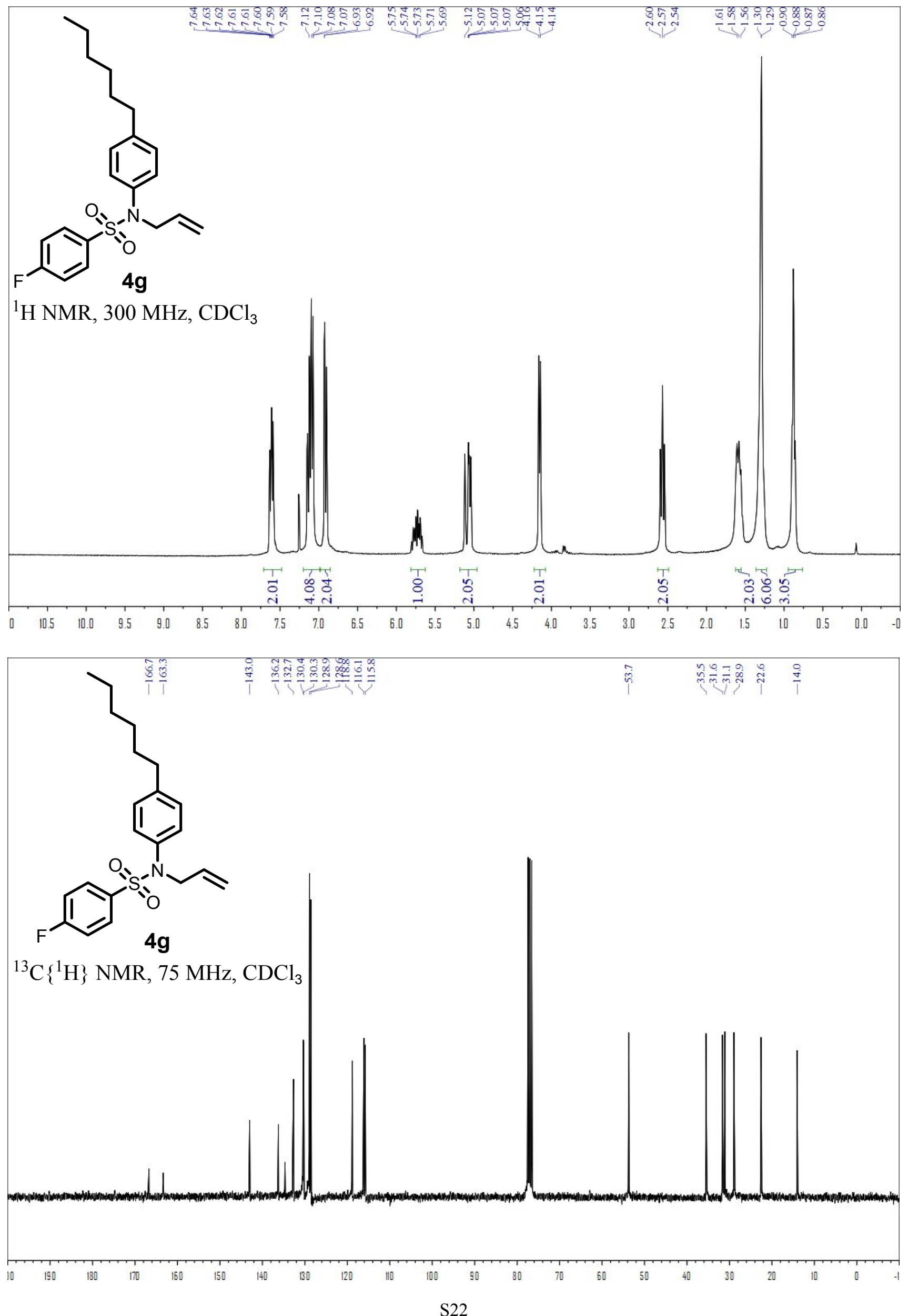


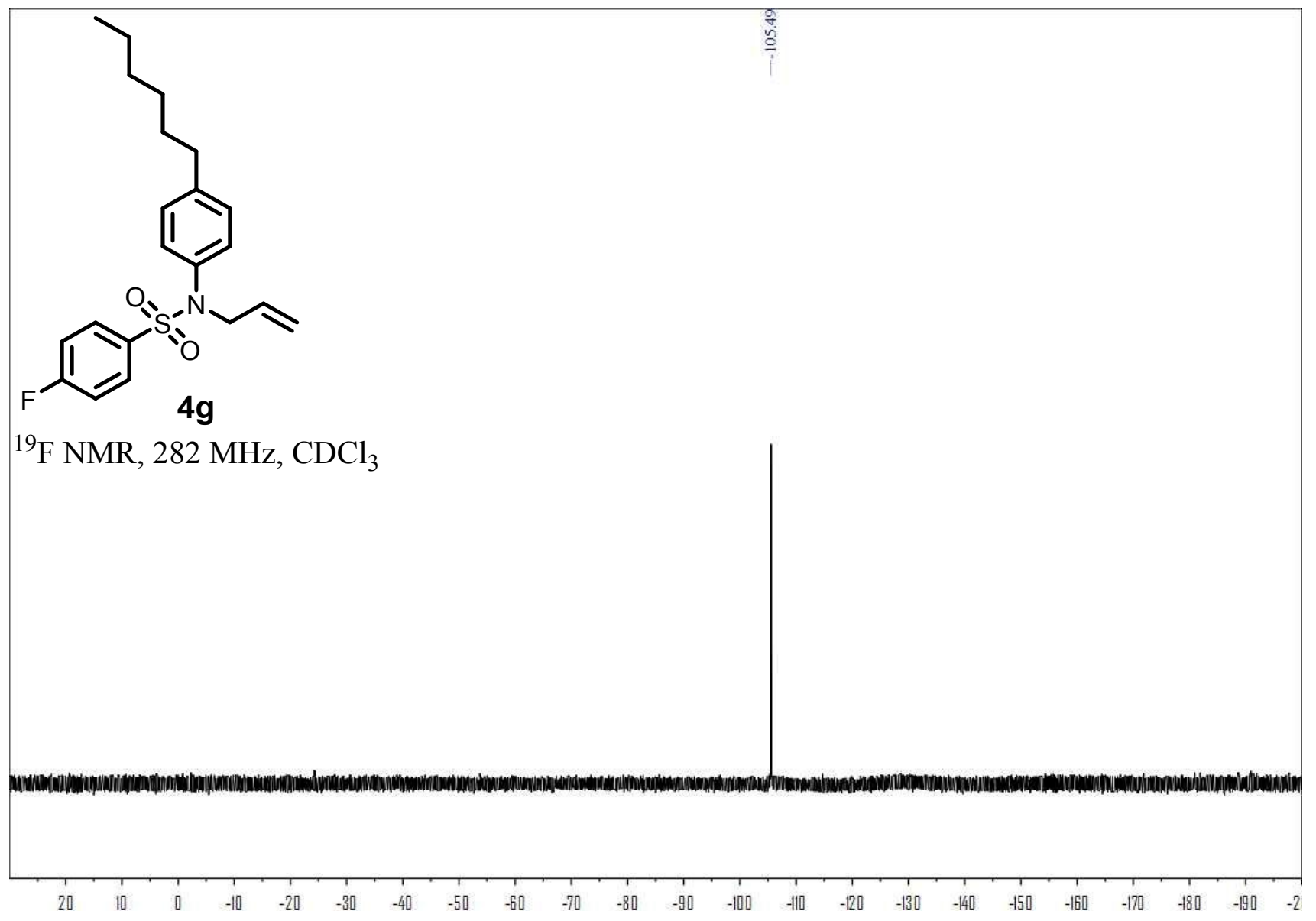




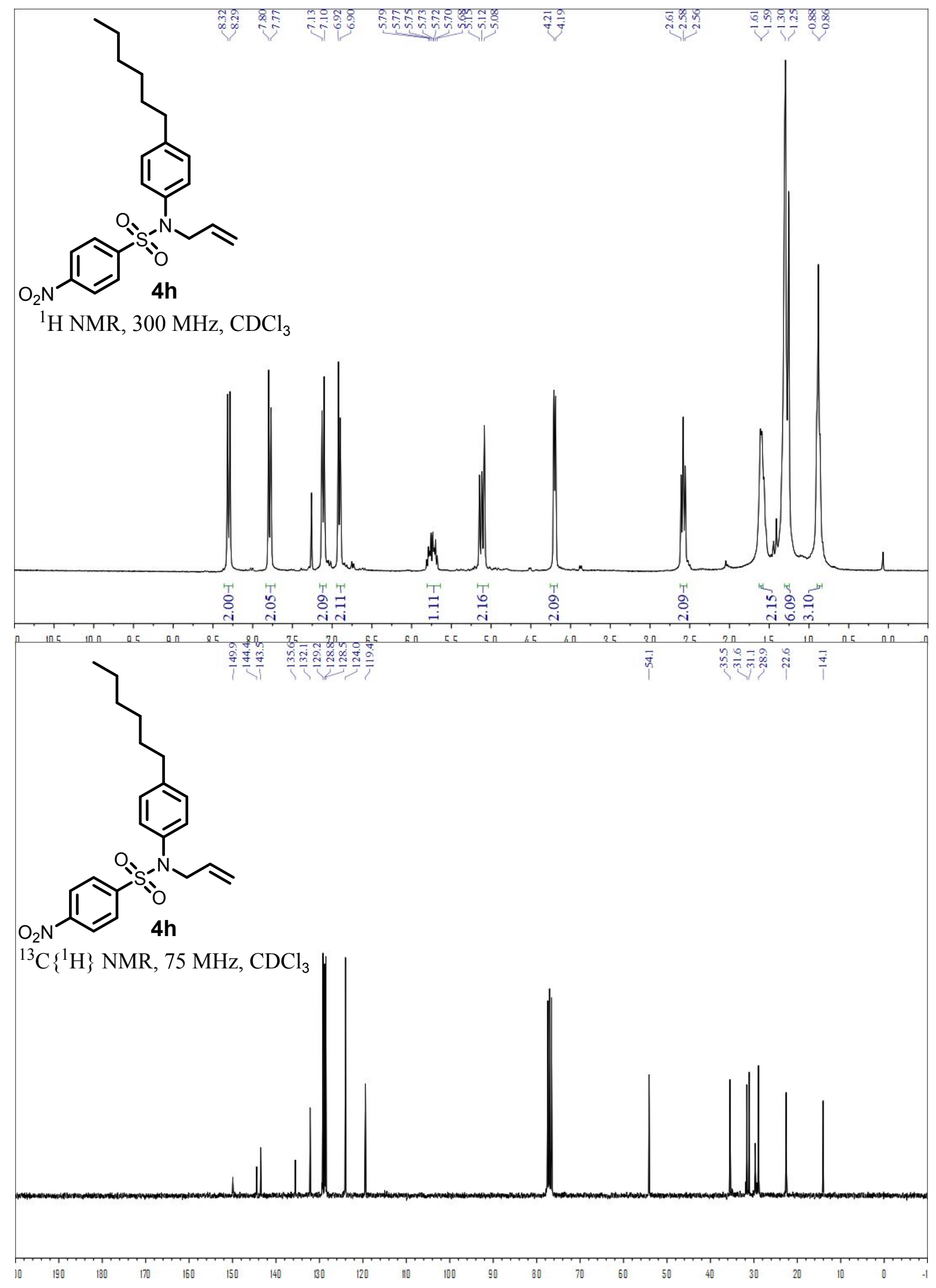




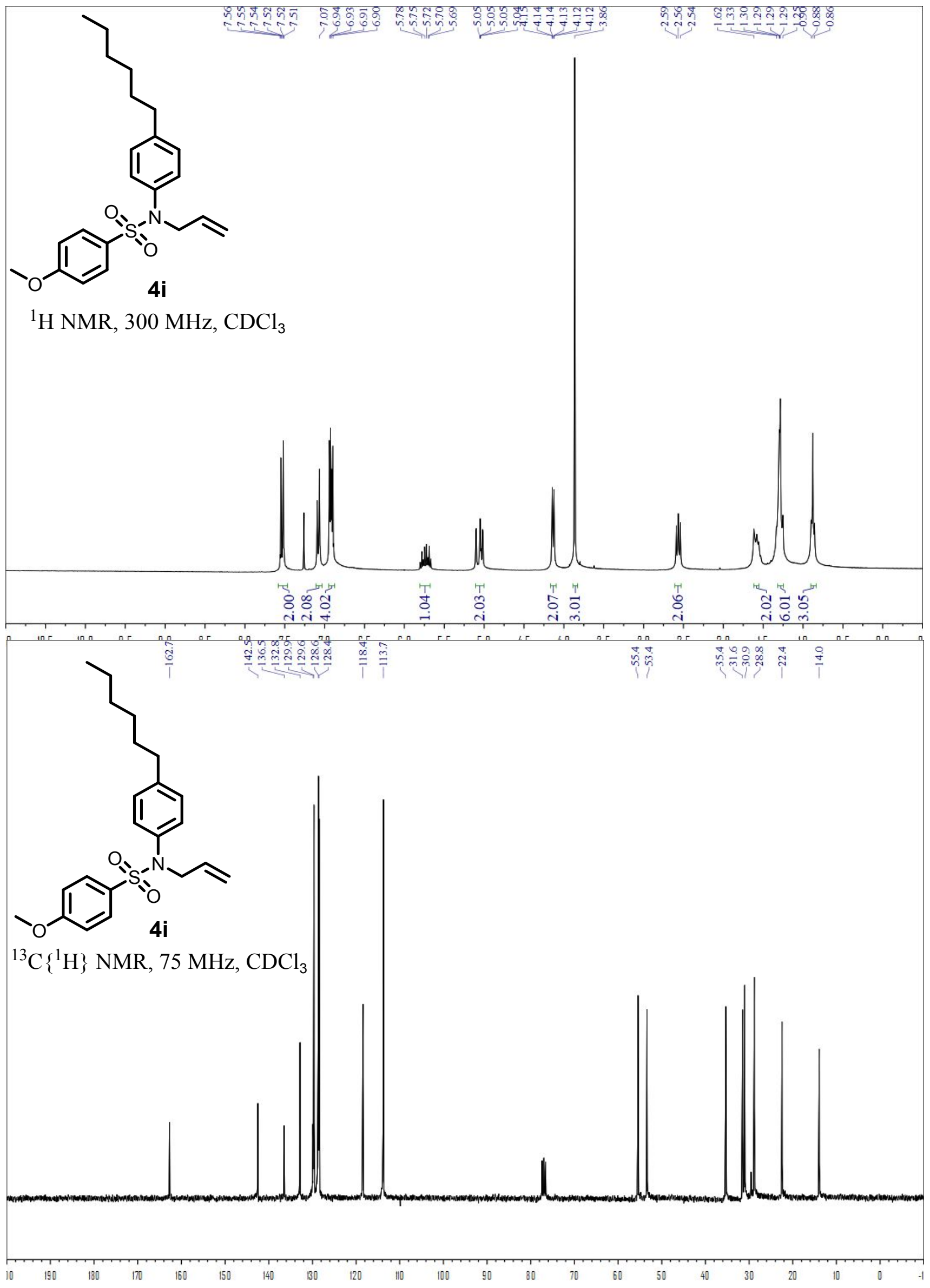



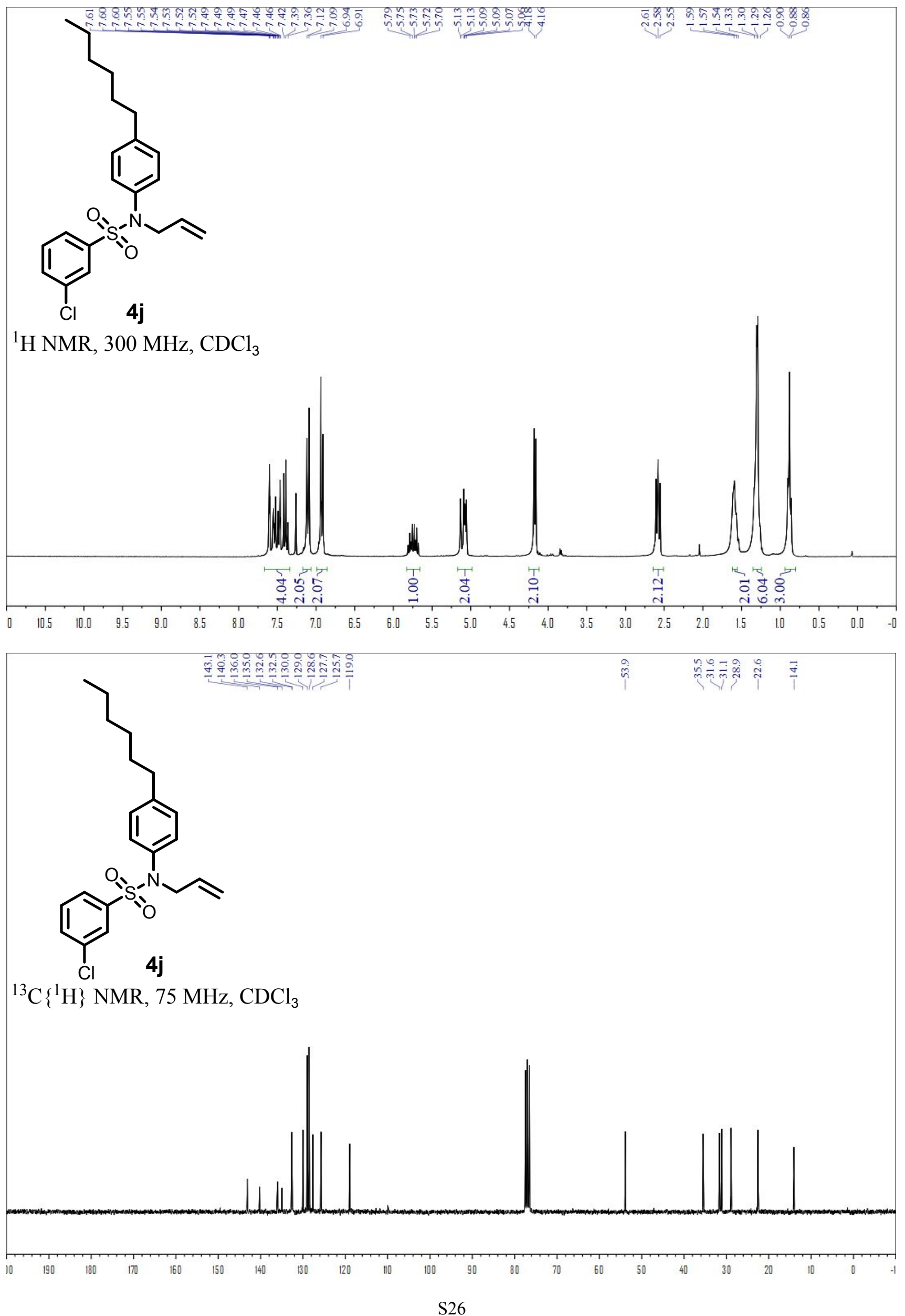

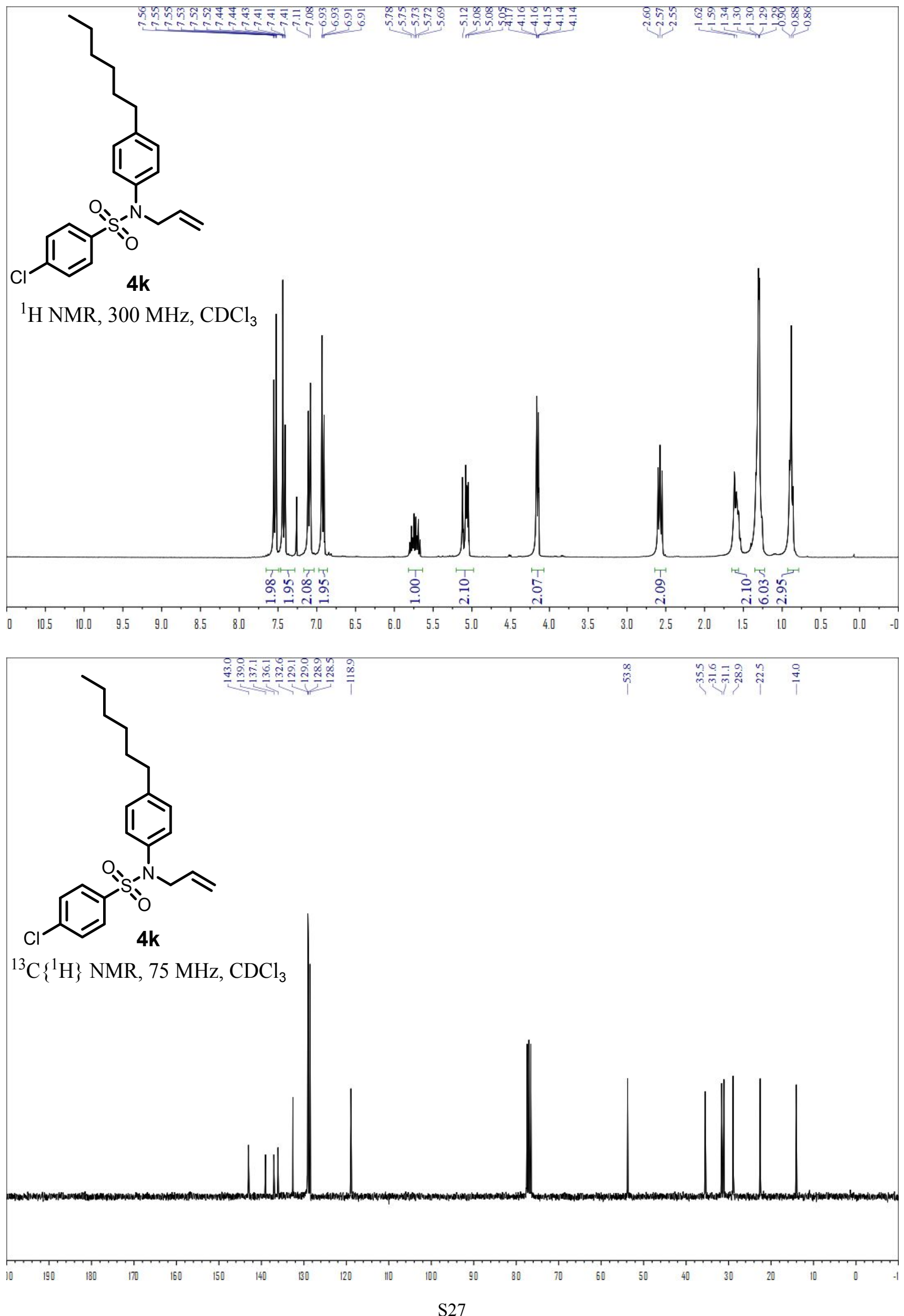

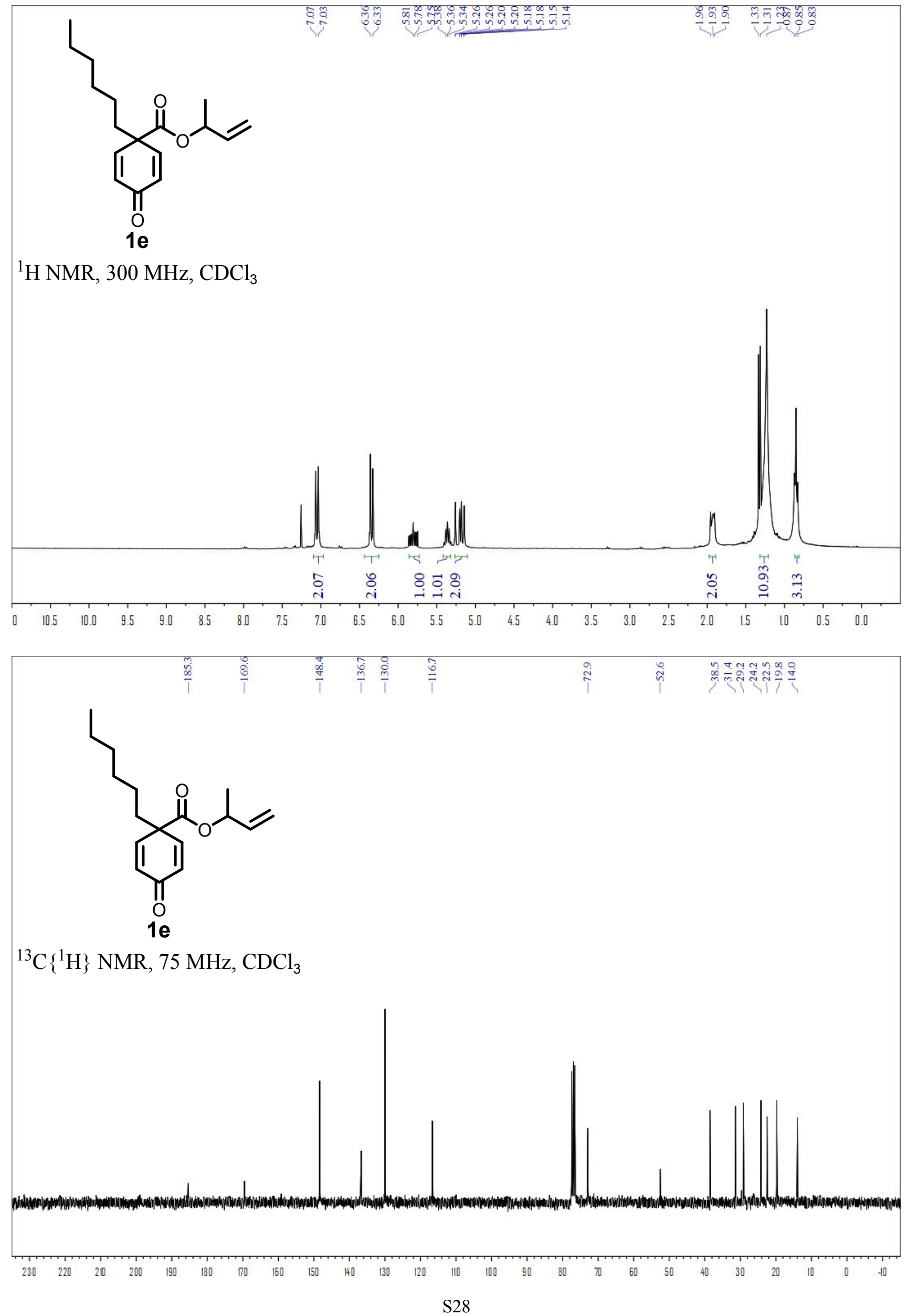

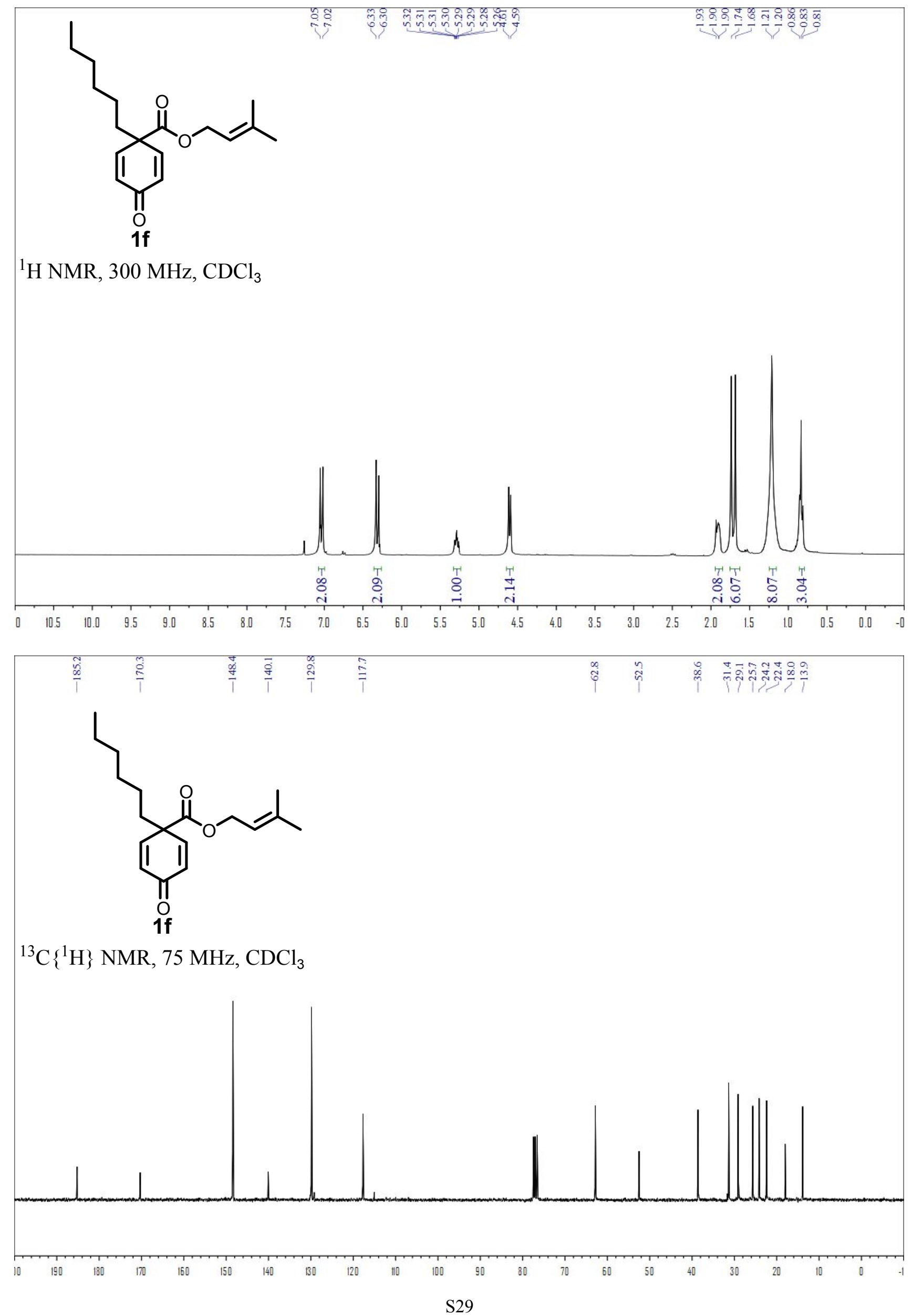

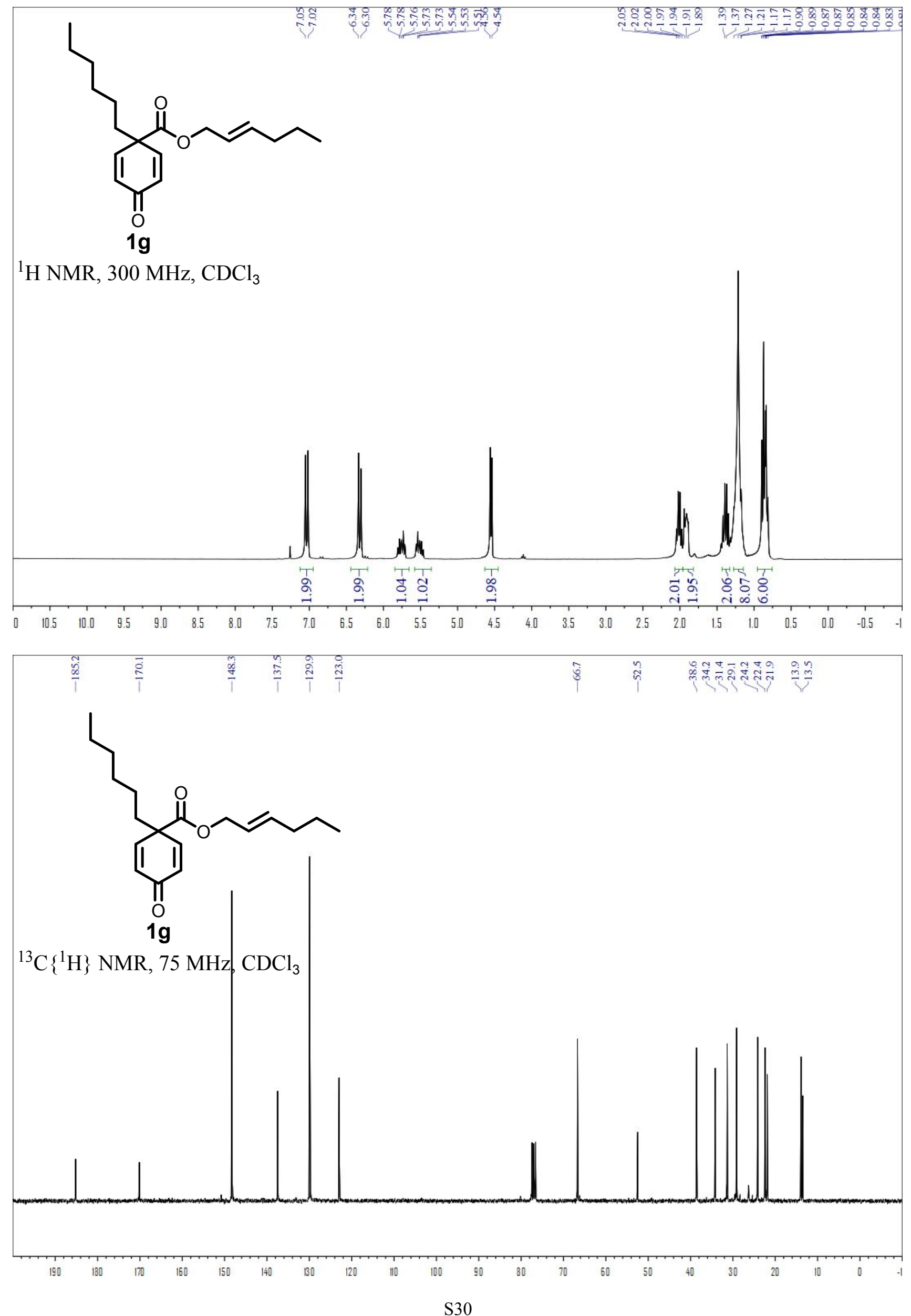

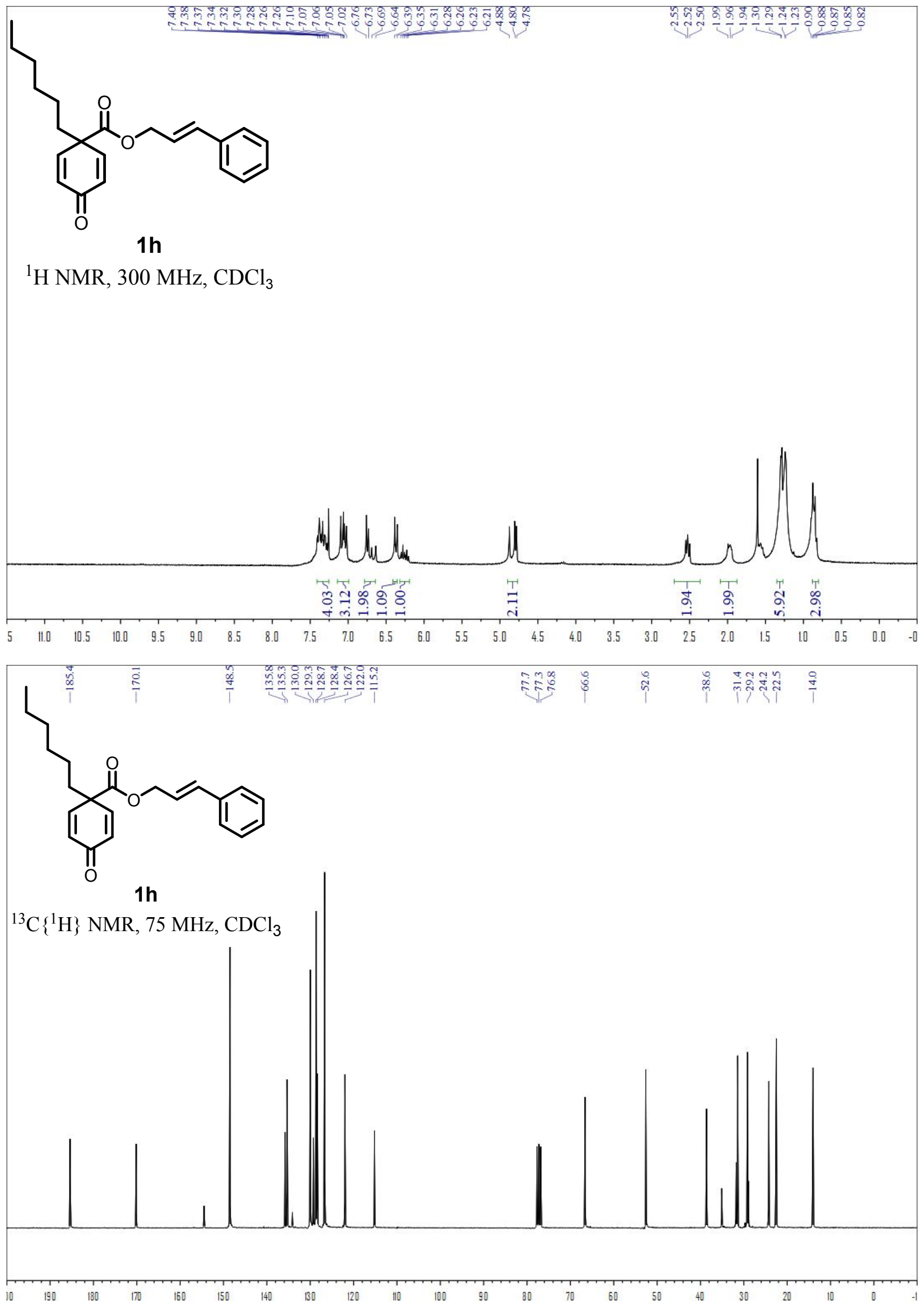


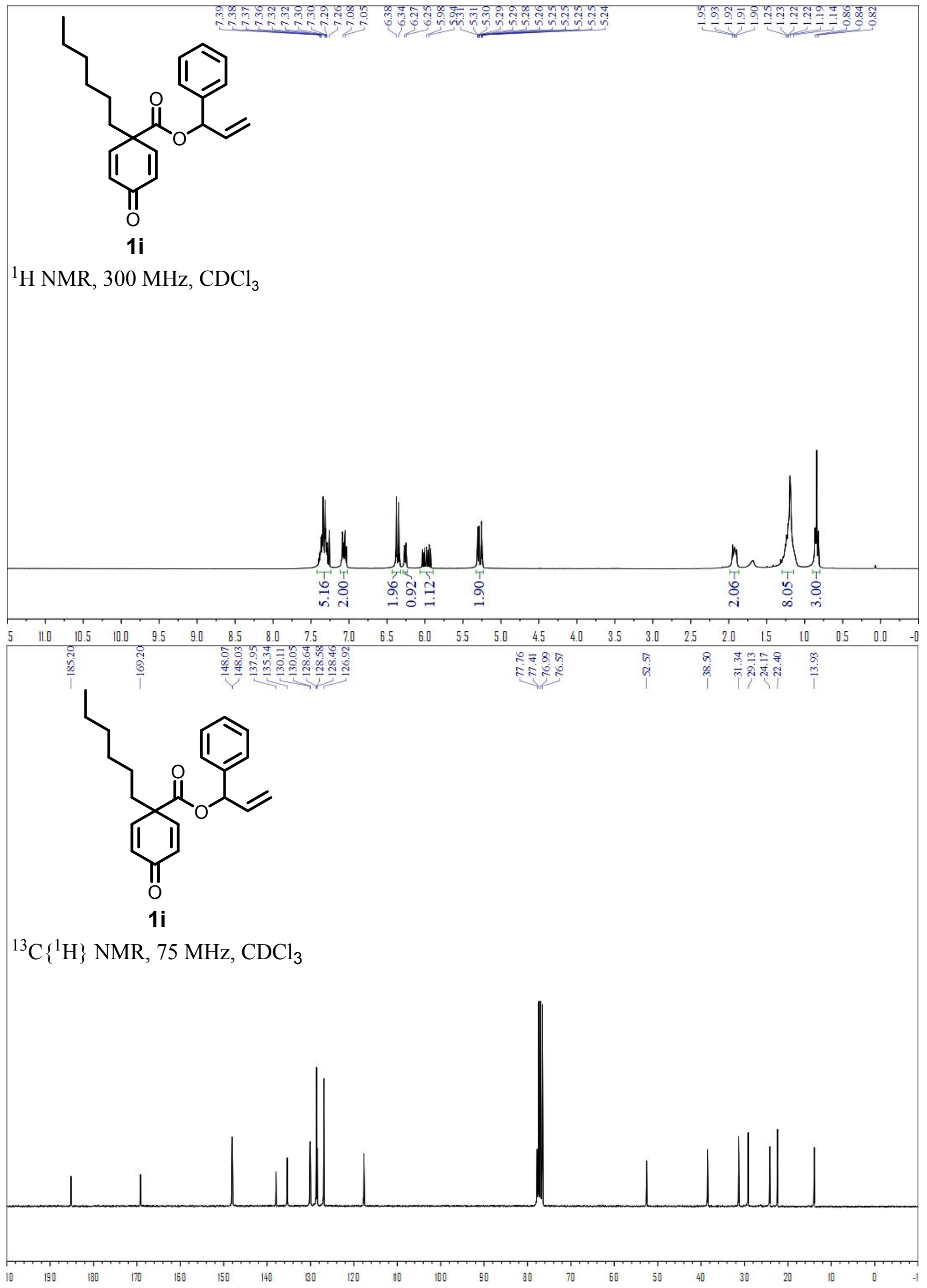




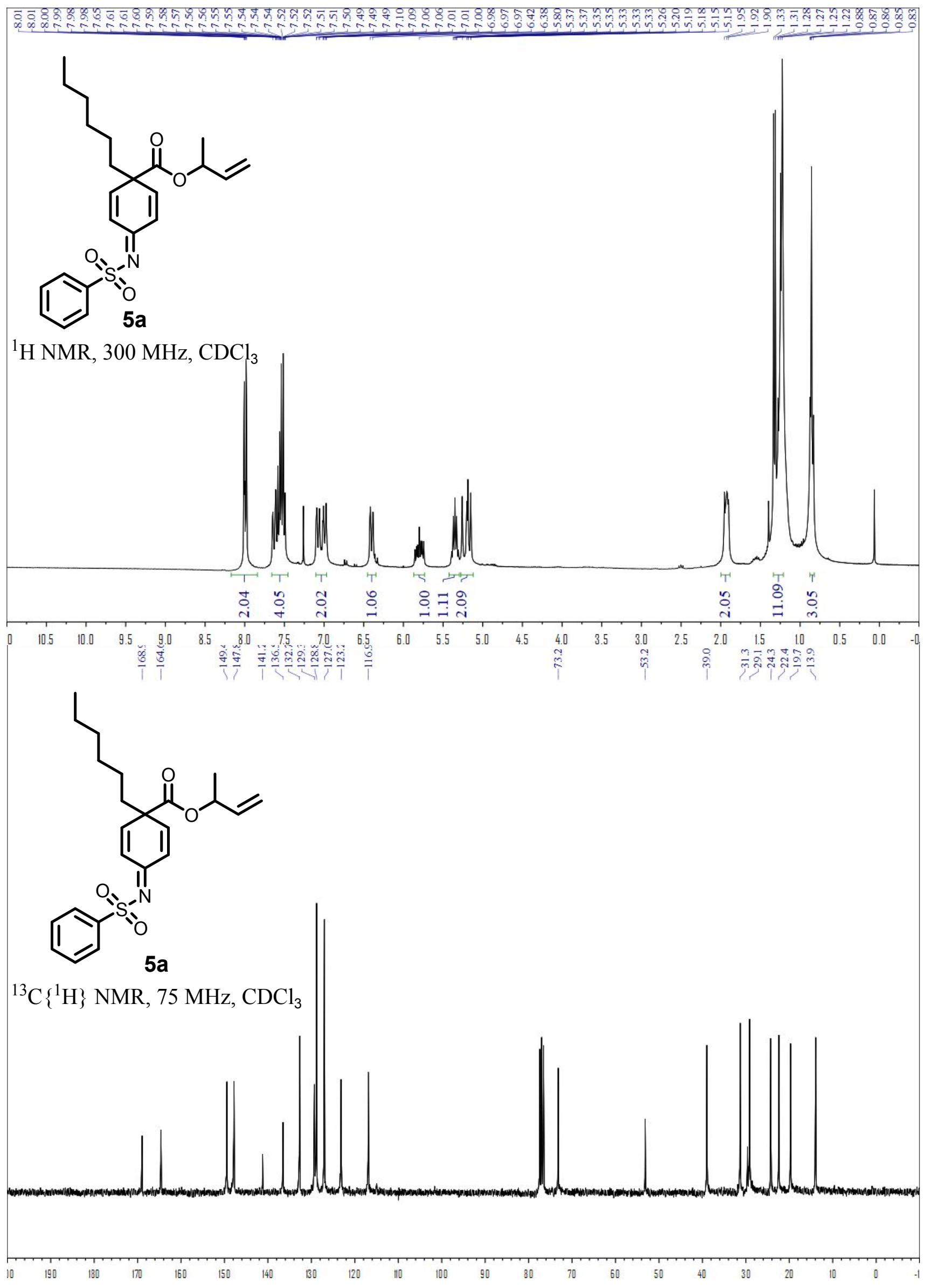




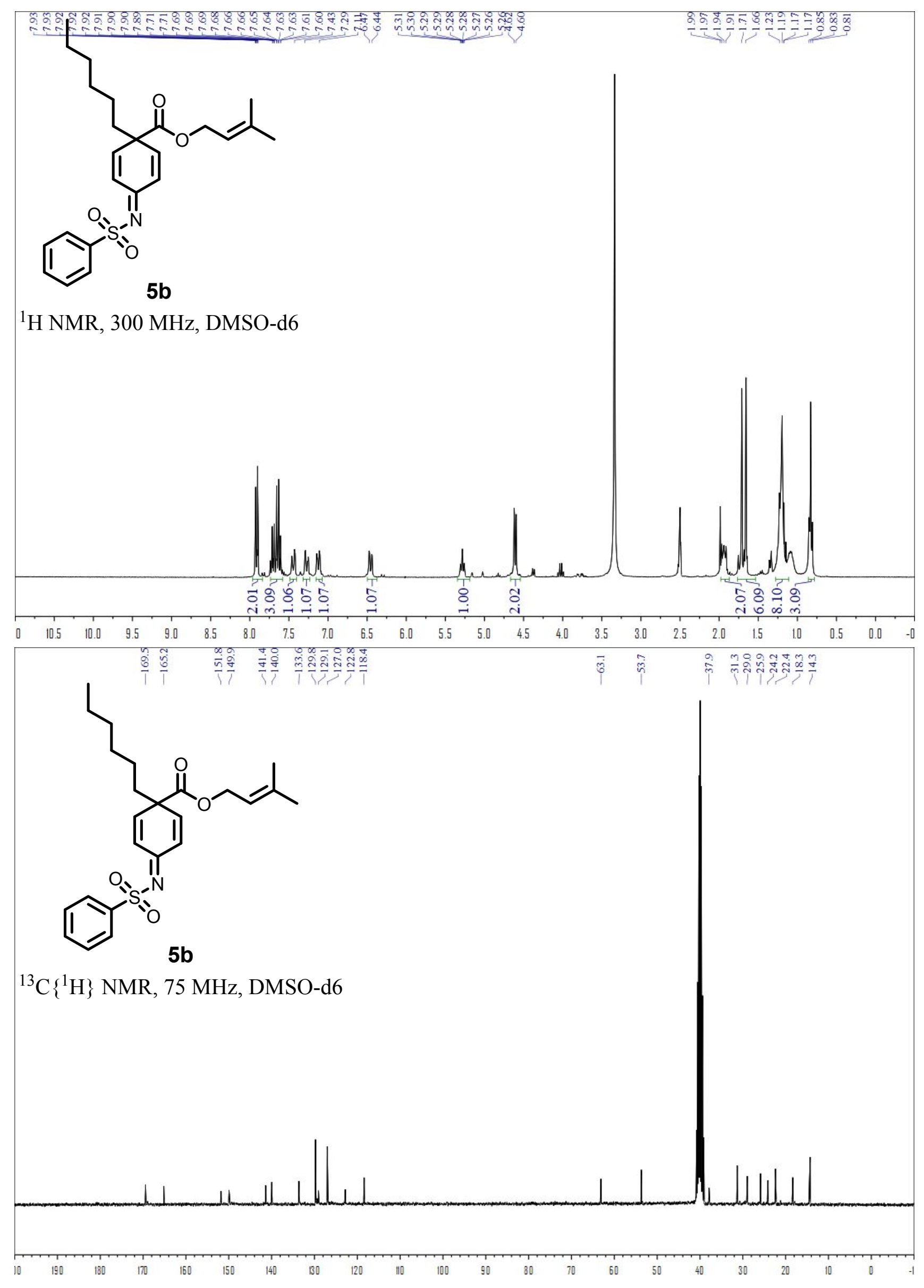



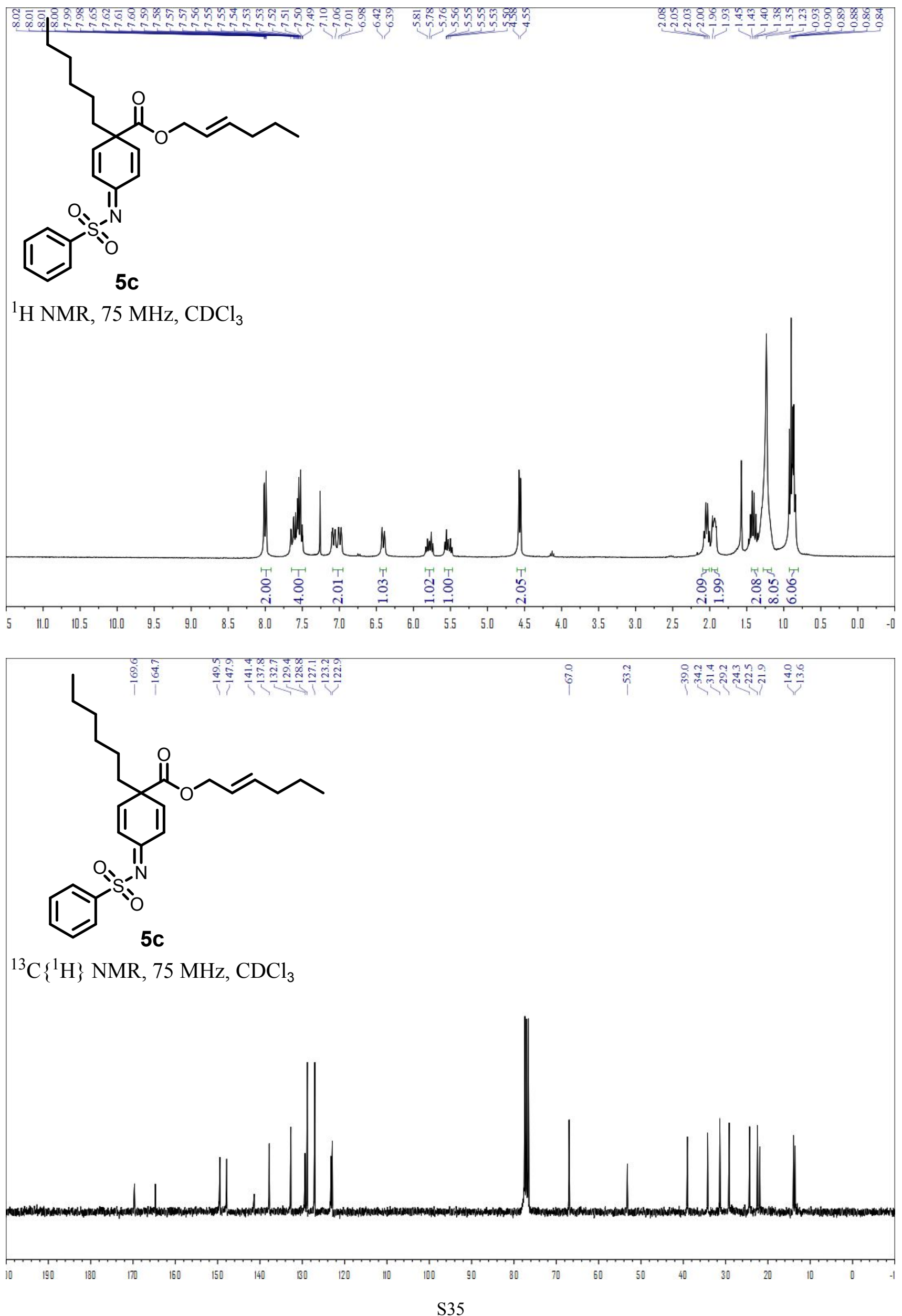

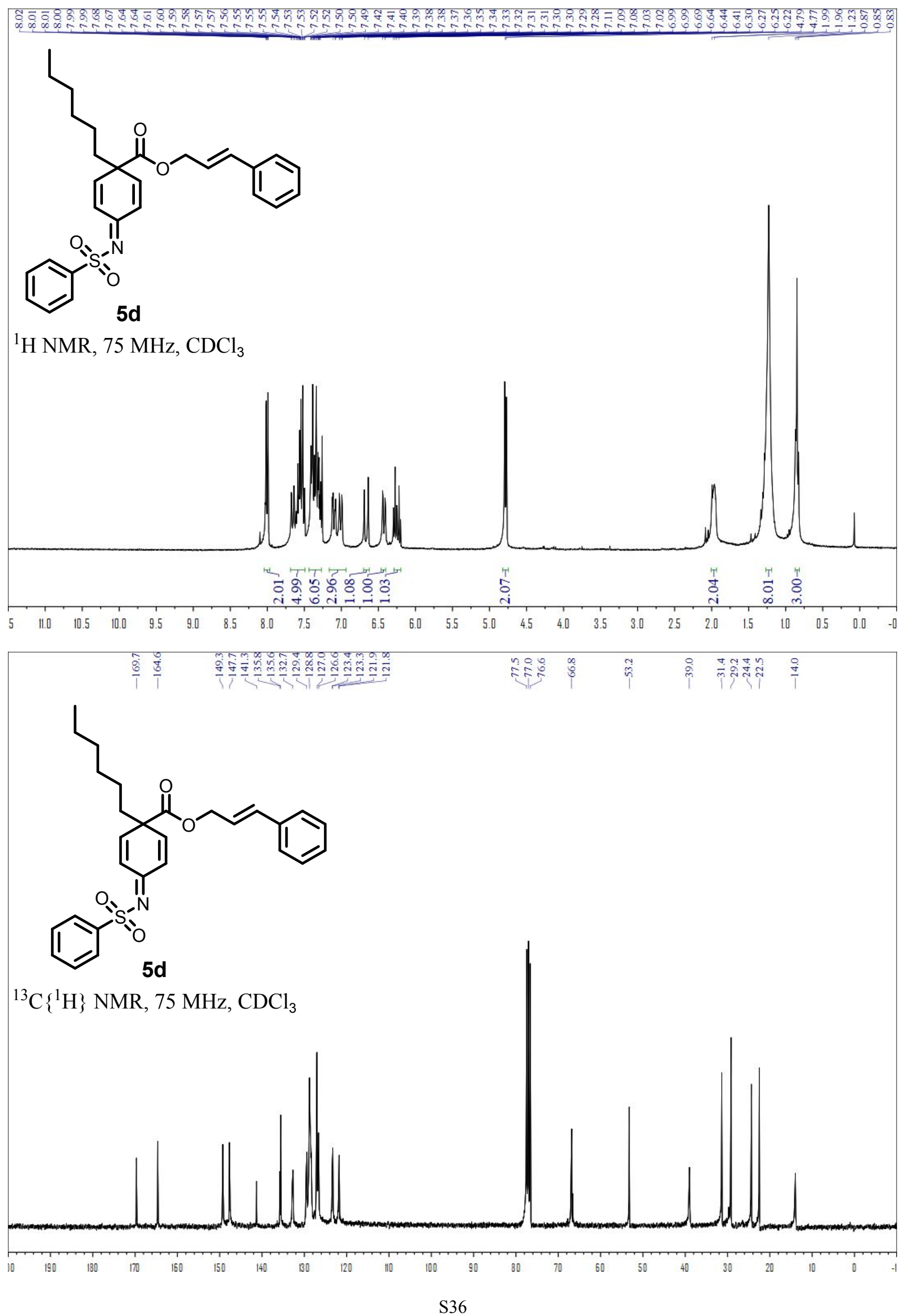


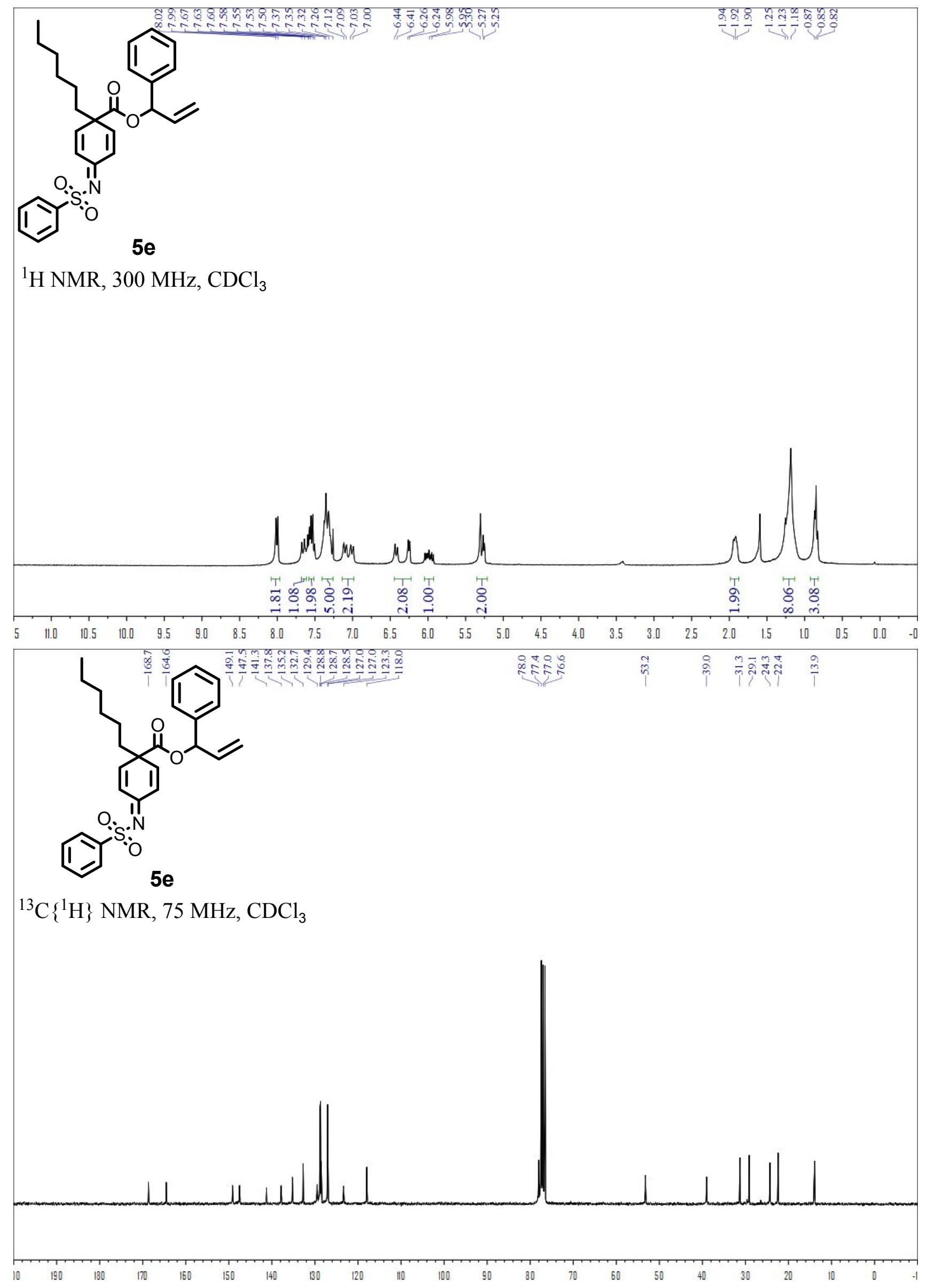




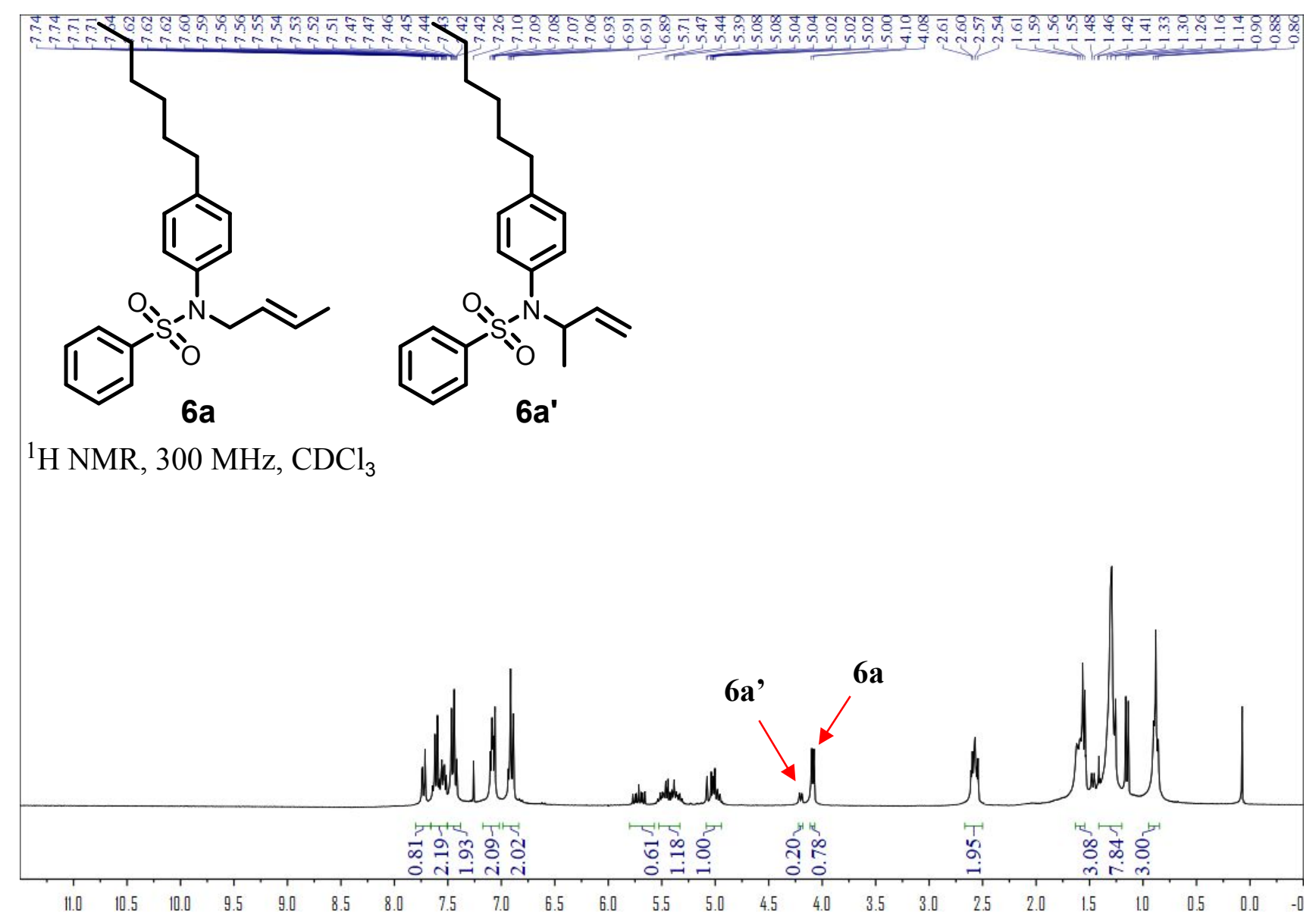




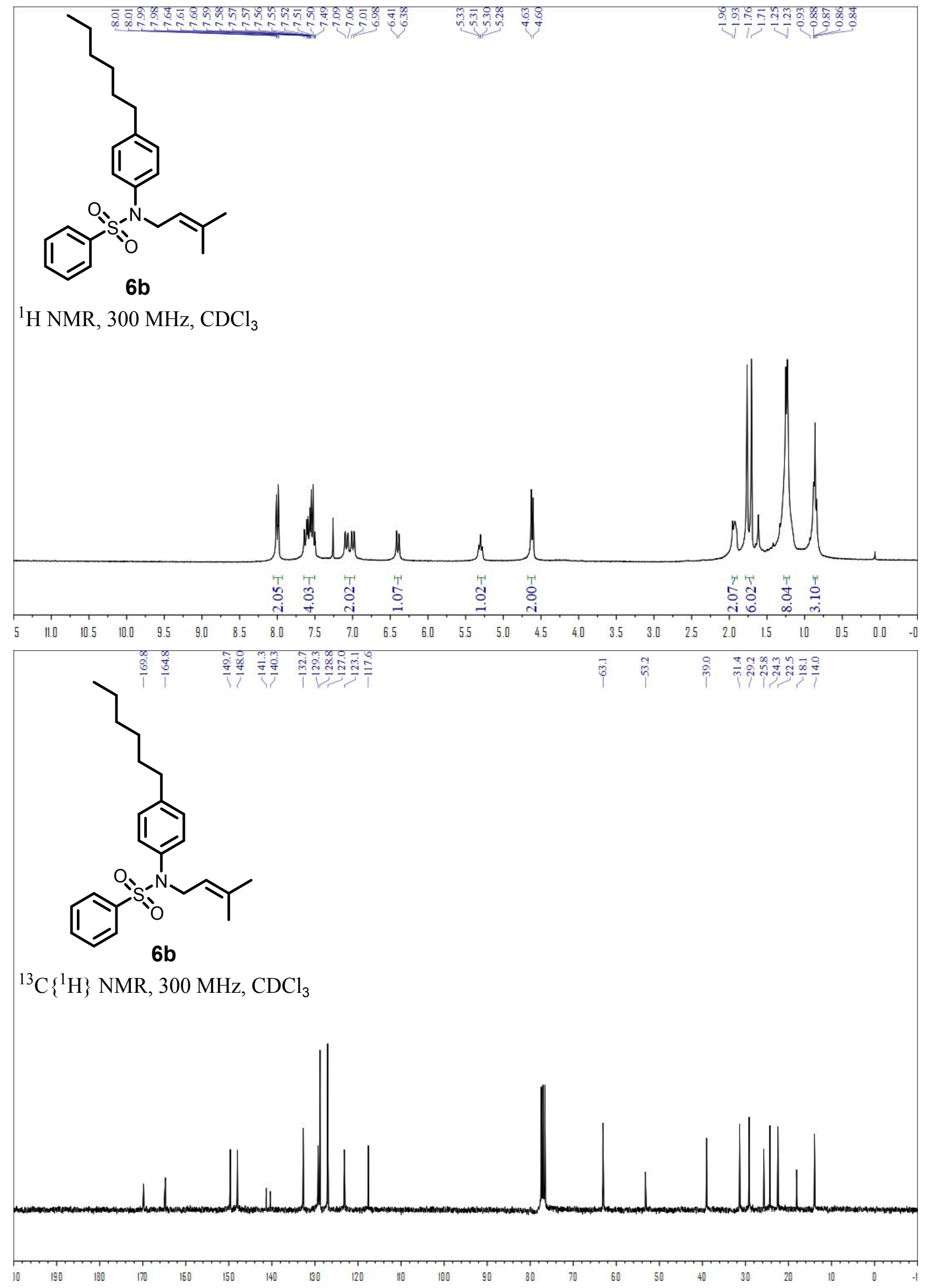



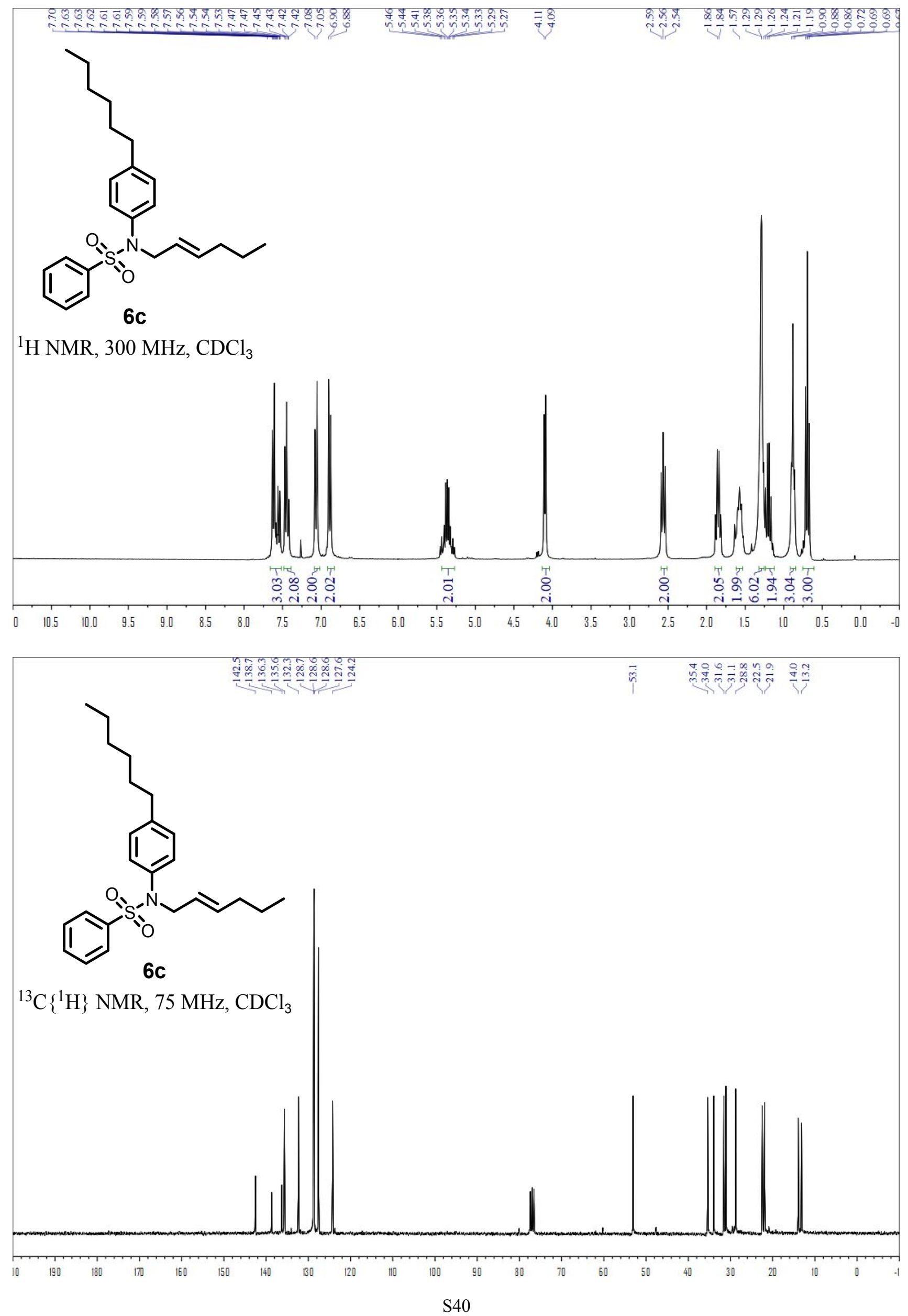

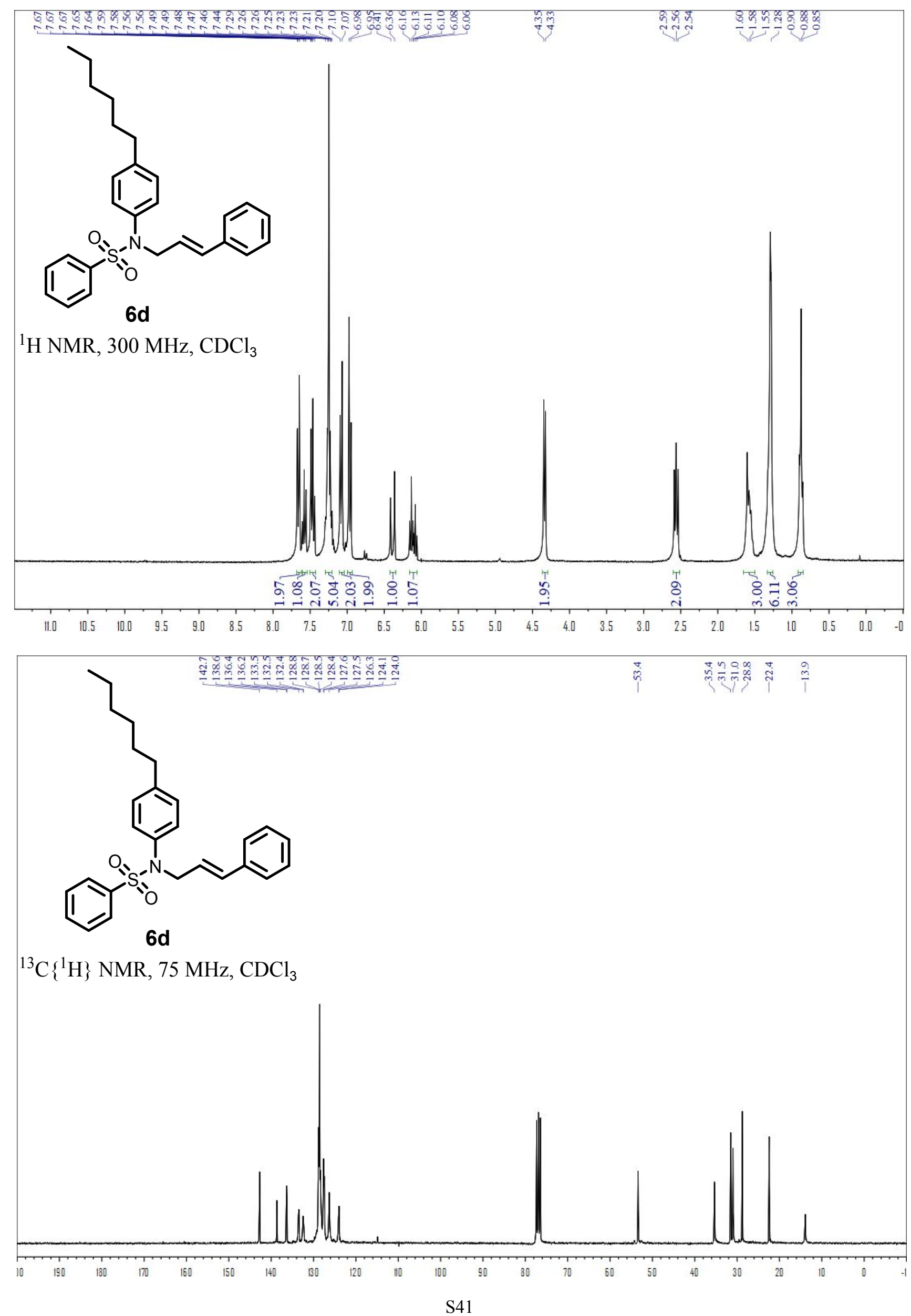

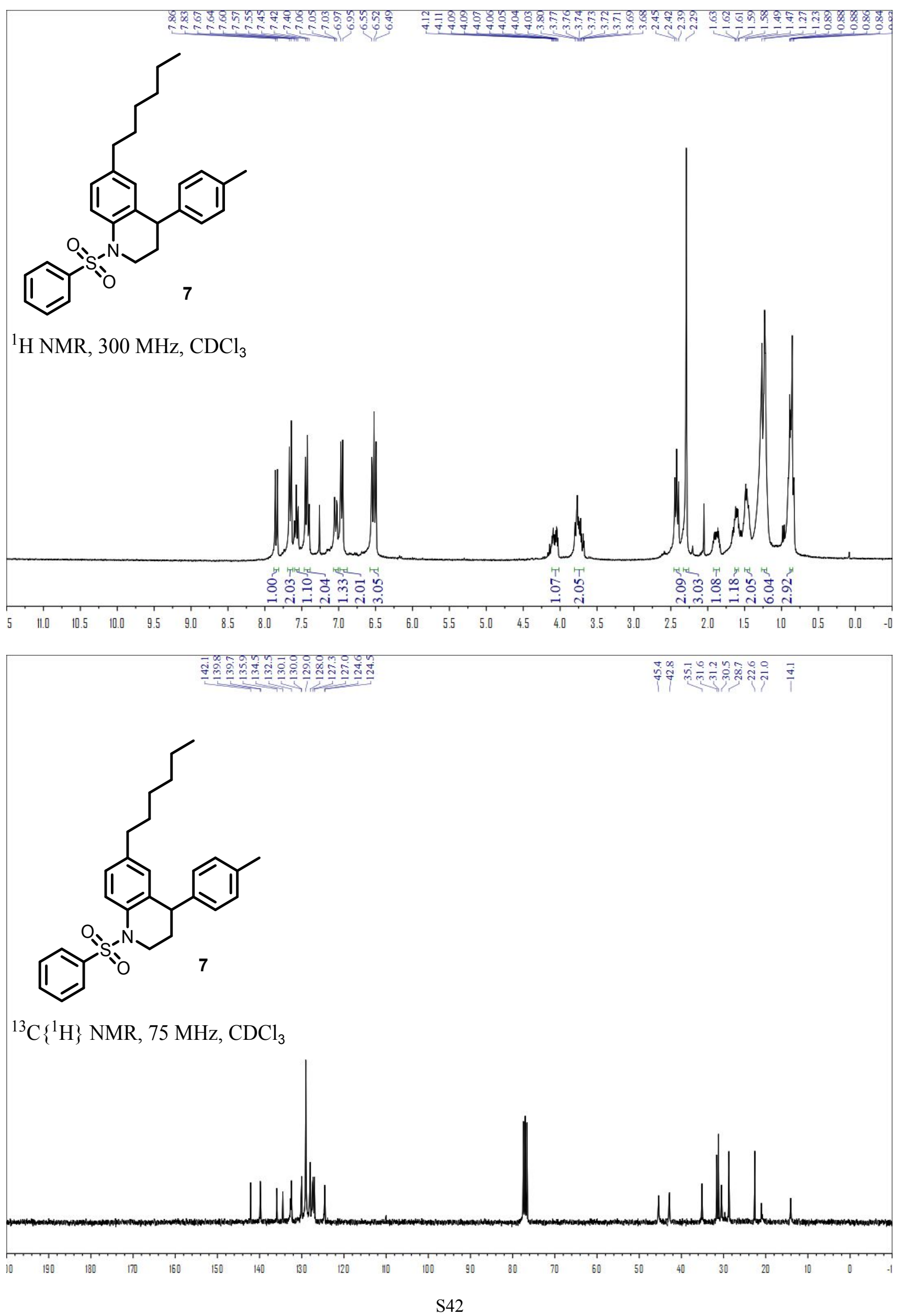


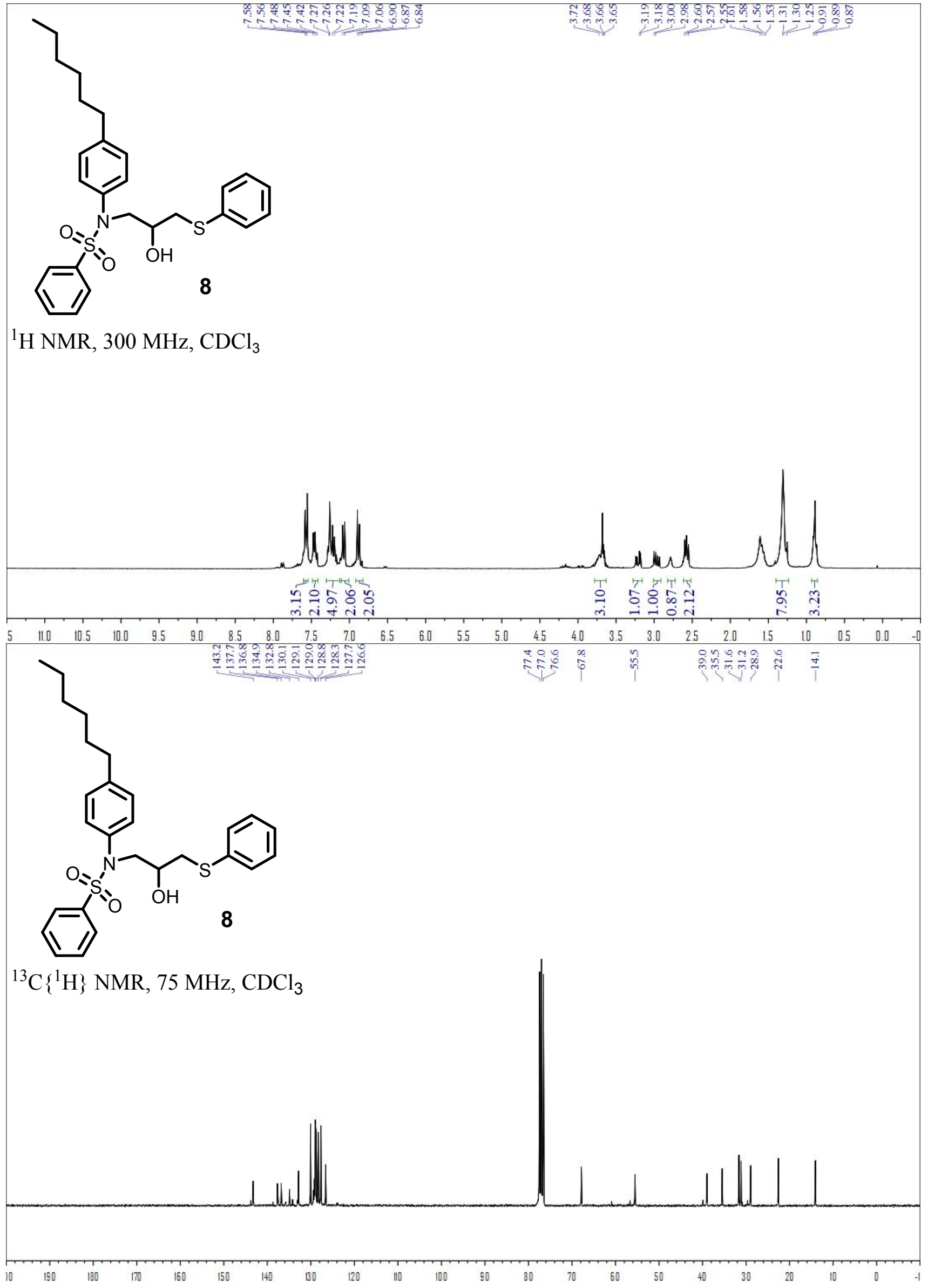

